\title{
MPRA
}

Munich Personal RePEc Archive

\section{The liquidity of dual-listed corporate bonds: empirical evidence from Italian markets}

MODENA, MATTEO and LINCIANO, NADIA and GENTILE, MONICA and FANCELLO, FRANCESCO

CONSOB

15 October 2014

Online at https://mpra.ub.uni-muenchen.de/62479/

MPRA Paper No. 62479, posted 02 Mar 2015 06:32 UTC 


\title{
The Liquidity of Dual-Listed Corporate Bonds: Empirical Evidence from Italian Markets
}

\author{
N. Linciano, F. Fancello, M. Gentile, M. Modena*
}

First Draft: October 2014

This Draft: February 2015

\begin{abstract}
We compute some indicators (zero-trade, turnover ratio, Amihud price impact, and Roll bid-ask spread) to examine the liquidity conditions of corporate bonds traded on the main Italian retail bond markets from January 2010 to June 2013. In order to compare market liquidity for identical securities, our analysis focuses on fragmented bonds, i.e. bonds traded concurrently on two different venues: either DomesticMOT and EuroTLX, or ExtraMOT and EuroTLX. As for bonds traded on DomesticMOT and EuroTLX, the Amihud and the Roll statistics suggest EuroTLX being more liquid. Moreover, irrespective of the trading venue, on average bank bonds are less liquid than bonds issued by non-financial companies, especially from 2011 due to the impact of the sovereign debt crisis. With regard to bonds traded across ExtraMOT and EuroTLX, the latter is characterized by better liquidity conditions, with bank bonds being more liquid than non-financial ones. Furthermore, we find evidence of better liquidity figures for Italian bonds (nationality), structured bonds (complexity), and securities with greater minimum trading size (MTS). We also find that bonds' features (issuers' nationality and industry; bonds' residual maturity, complexity, rating, etc...) affect liquidity differently depending upon the trading venue, thus supporting the view that market microstructure may play a relevant role. Finally, we investigate the effect of fragmentation by comparing the liquidity of dual-listed bank bonds fragmented across DomesticMOT and EuroTLX with otherwise similar bank bonds traded exclusively on DomesticMOT. Italian fragmented bank bonds turn out to be slightly more liquid than similar Italian bonds traded exclusively on DomesticMOT; whereas, the opposite holds for foreign bank bonds. However, overall there is not a clear-cut evidence on the effect of fragmentation on bond liquidity, probably because it is intertwined with bonds' attributes, such as the issue size (in our sample, higher for the Italian bank bonds).
\end{abstract}

JEL Classification: G01, G10, G12, G18

Keywords: liquidity risk, dual-listed bonds, corporate bonds, market microstructure.

\footnotetext{
* Consob, Research Department, Unit of Economic Studies. Via G.B. Martini, 3; 00198, Rome, Italy. Corresponding author: Nadia Linciano, n.linciano@consob.it. The authors thank Giovanni Petrella, Andrea Resti, Juan Roboredo, Giovanni Siciliano and the participants to the Portuguese Financial Network 2014 Conference, held in Vilamoura, Portugal, on June 18-20, 2014, for useful comments to an earlier version of the paper. Of course, the authors are the only responsible for errors and imprecisions. The opinions expressed here are those of the authors and do not necessarily reflect those of Consob.
} 



\section{Introduction}

The determinants of liquidity of corporate bonds have long been of interest for regulators and academics. Although the definition of liquidity is straightforward since it is the ability to trade quickly at a low cost (O'Hara, 1995), liquidity measurement is still quite challenging. Different indicators have been proposed to capture some relevant aspects affecting liquidity: immediacy (the speed of orders execution), tightness (transaction costs), market depth (size of the order needed to move the price), and price impact (the price change following the execution of orders of a certain amount). Liquidity indicators can be computed following either a trade-based or an order-based approach, broadly defined as ex-ante and ex-post measures, respectively.

Liquidity is crucial for any investor who has to determine the size, the timing, and the venue of orders execution. In the European framework, the choice of the trading venue has become relevant especially since the introduction of the Directive 2004/39/EC (MiFID henceforth) in November 2007. MiFID set a new regulation of trading venues ${ }^{1}$ and envisaged the abolition of the so called "concentration rule" (whereby investment firms were required to route clients' orders to regulated markets only). The new legislative framework aims at promoting competition and, through such a way, enhancing investors' protection.

When transposing MiFID to the national law system, Italy decided to extend both pre- and posttrade transparency rules to non-equity markets, although the Directive envisaged such rules for equity markets only. Moreover, the Italian securities regulator (CONSOB) issued a specific regulation, recommending intermediaries to adopt firm transparency measures within the distribution process of illiquid products (bank bonds, financial insurance products and derivatives) ${ }^{2}$ to retail customers. The massive participation of retail investors to Italian bond markets has contributed to shape the Italian legal framework. As a matter of fact, direct retail holdings of corporate bonds, especially bank securities, are far more extensive in Italy than in other EU countries. $^{3}$ For these reasons, corporate bond markets accessible by retail investors have proliferated. Nevertheless, both illiquidity and infrequent trading still remain open issues and represent significant risk factors undermining investors' protection.

Bonds can be traded on more than one venue, thus raising the question about whether, and to what extent, fragmentation affects liquidity. Therefore, fragmentation of corporate bonds across multiple trading venues remains a key policy issue in Italy. On the one hand, fragmentation may affect liquidity and, in turn, the position of retail investors willing to sell securities at a fair price. On the other hand, the point is relevant for issuers as well, since liquid markets may encourage firms to raise debt capital, a strategic opportunity to accomplish effective diversification of funding sources.

This paper investigates both the liquidity conditions and the determinants of trading of dual-listed bonds (henceforth, also fragmented bonds, i.e. bonds whose trade takes place concurrently on two different trading venues). In particular, we analyze the liquidity of 409 bonds traded on EuroTLX (a multilateral trading facility -MTF-) and either on DomesticMOT (a regulated market) or on ExtraMOT (MTF) from January 2010 to June 2013. Since bonds traded on DomesticMOT cannot be exchanged on ExtraMOT (and vice-versa) during the observed period, there are two samples of

1 In particular, the trading venues were classified into regulated markets, multilateral trading facilities (MTFs) and systematic internalizers.

2 Communication no. 9019104, "The duty of the intermediary to act with due correctness and transparency on distribution of illiquid financial products" (2 March 2009). The Communication is part of the MiFID "level 3" measures for the Intermediaries' Regulation. The key point is that investors should be allowed to disinvest at a fair price and within a reasonable period of time.

3 At the end of 2013 Italian households' direct investment in corporate bonds accounted for about 14\% of their financial wealth, equivalent to the figure referred to the Italian government bonds (Consob, 2013). 
dual-traded securities: the first sample includes bonds traded across DomesticMOT and EuroTLX; the second sample includes bonds traded on ExtraMOT and EuroTLX.

We consider four indicators to measure liquidity: 1) the percentage of non-trading days (the zerotrade statistics); 2) the turnover ratio (i.e. the ratio between turnover and the outstanding amount); 3) the price impact (the Amihud statistics); 4) the bid-ask spread estimated using the Roll statistics.

Liquidity levels of bonds traded on both DomesticMOT and EuroTLX are similar across the two venues when using the zero-trade indicator and the turnover ratio; whereas, liquidity figures are better on EuroTLX if we consider the price impact (Amihud) and trading costs (Roll spread). Bank bonds ( $87 \%$ of the sample) are the main driver of such an outcome. On the contrary, non-financial bonds traded on DomesticMOT tend to be more liquid than those traded on EuroTLX.

On average, EuroTLX turn out to be more liquid for bonds traded across ExtraMOT and EuroTLX. In addition, irrespective of the trading venue, on average bank bonds seem to be more liquid than non-financial bonds; however, bank bonds become less liquid than non-financial bonds during the sovereign debt crisis.

Differences in the liquidity of dual-listed bonds across trading venues might depend on microstructural features. We find that securities' characteristics (such as minimum trading size, coupon type, complexity, issuer sector and nationality) may impact differently on liquidity measures depending upon the trading venue, thus suggesting that market microstructure plays a relevant role. Such an evidence is corroborated by the multivariate analysis (controlling for bond features, liquidity conditions change across trading venues).

Finally, the paper sheds light on the effect of fragmentation by comparing liquidity levels of bank bonds fragmented across DomesticMOT and EuroTLX with otherwise similar bank bonds traded on DomesticMOT only. We show that bonds issued by Italian banks traded both in DomesticMOT and EuroTLX exhibit similar or higher liquidity (depending on the measure adopted) than otherwise similar Italian bank bonds traded exclusively on DomesticMOT; whereas, the opposite holds for bonds issued by foreign banks.

To our knowledge, this is the first paper to investigate the liquidity of dual-listed bonds and the effect of fragmentation on retail corporate bond markets, thus providing new empirical evidence on the contribution of transparency and market microstructure rules on the development of an integrated secondary market. Indeed, so far, given the size of the Italian public debt, the vast majority of the studies on the Italian case have focused on institutional trading on the government bond market, leaving overshadowed the retail side. In this respect, our paper has important policy implications given that the recent MiFID review envisages greater transparency in non-equity markets. $^{5}$

The rest of the work is organized as follows. Section 2 summarizes the institutional features and the microstructure of DomesticMOT, ExtraMOT and EuroTLX. In Section 3 we describe the dataset. Liquidity indicators and figures are presented in Section 4. In Section 5 a random effect panel logit model is applied to examine the determinants of the probability of trading across the different trading venues. Section 6 employs a matched sample approach to analyze the impact of fragmentation on liquidity for a sample of bank bonds traded on DomesticMOT. Section 7 concludes.

4 The use of all these indicators is supported by the principal component analysis since liquidity of dual-listed bonds cannot be effectively summarized by one single indicator over the sample period. Liquidity appears to result from the even contribution of the four measures.

5 Discussion paper available at http://www.esma.europa.eu/system/files/2014 548_discussion_paper_mifid-mifir.pdf. 


\section{The Italian corporate bond markets: institutional and microstructural features}

DomesticMOT, ExtraMOT, and EuroTLX are the main Italian trading venues for retail investors to trade corporate bonds. ${ }^{6}$ MOT and ExtraMOT (respectively, a regulated market and a MTF) are owned and managed by Borsa Italiana S.p.A.; while EuroTLX (a MTF) was owned by two major Italian bank groups (Unicredit and Intesa SanPaolo through Banca IMI Spa) till September 2013, when Borsa Italiana bought a majority stake.

Established in 1994, MOT is a regulated market split in two segments: DomesticMOT and EuroMOT. MOT trades both Italian and foreign government securities, corporate bonds issued by both domestic and foreign companies, supranational and asset-backed securities. ${ }^{7}$

ExtraMOT was launched in 2009. Bonds and other debt securities are admitted to trading on ExtraMOT at the proposal of Borsa Italiana S.p.A. or at the request of an intermediary. Admission is allowed provided securities are already traded on a regulated market. However, since May 2011, unlisted bank bonds can also be admitted to trading on ExtraMOT upon request of the issuer.

The regulatory framework of the Italian bond markets is set by the MiFID and by the Italian law (Testo unico della finanza - Consolidated Law on Financial Intermediation). As said, MiFID abolished the concentration rule and set mandatory pre- and post-trade transparency obligations for equity markets. However, member States were allowed to extend such rules to non-equity platforms. ${ }^{8}$ Accordingly, the Italian legislator opted for such an extension when transposing MiFID into the national system and CONSOB issued more detailed regulation. The Authority adopted a "flexible approach" whereby regulated markets (MTFs and systemic internalizers -Sis-) were required to establish and maintain differentiated transparency regimes. MTFs could set weaker requirements provided instruments were already listed on a regulated market. In addition, all trading venues were allowed to design their own pre-trade transparency rules taking into account the microstructure, the type of the financial instrument, the amount traded, and the market type. ${ }^{9}$

All bond markets managed by Borsa Italiana (DomesticMOT and ExtraMOT) are order-driven markets. On DomesticMOT, it is envisaged the optional presence of a liquidity provider (or specialist), subject to specific minimum mandatory trading quantity quotations. ${ }^{10}$ Such a requirement holds also for ExtraMOT, where the intermediary that has requested admission to trading of a certain security shall act itself as a specialist for such financial instrument. ${ }^{11}$ Trading takes place during an opening auction phase (from 8:00 am to 9:00 am) and a continuous trading phase (from 9:00 am to 5:30 pm). Borsa Italiana establishes the minimum trading size consistently with the minimum lot size laid down in the bond rules and considering, among other things, cost effectiveness in order execution.

The microstructure of EuroTLX is hybrid, combining both order and quote driven features. Liquidity is guaranteed both by a competitive and continuous auction mechanism (orders and quotes are matched according to price and time priority) and by the presence of (at least) one

6 We ruled out the fourth trading venue for corporate bonds (HI-MTF) given its negligible market share.

7 Monte Titoli clears trades on DomesticMOT, while Euroclear and Clearstream clears trades on EuroMOT.

8 See art. 27-30 and 44-45 of Directive 2004/39/EC, and Chapter IV (on Transparency) of Commission Regulation (EC $\left.\mathrm{N}^{\circ} 1287 / 2006\right)$.

9 See art. 79-bis, paragraph 2, of Legislative Decree no. 58 of 24 February 1998 - Consolidated Law on Financial Intermediation. Consob implemented this faculty in artt. 32 -34 of its Markets Regulation n. 16191 of 29 October 2007. 10 See for instance art. 4.4.1 of 2014 Borsa Italiana Market Rules.

11 See art. 300 on ExtraMOT 2010 Market Rules. Currently (2014) the specialist requirements apply also to financial instruments listed at issuers' request. 
liquidity provider for each financial instrument ${ }^{12}$. The liquidity provider must quote continuously a minimum quantity ${ }^{13}$ during trading hours (from 9:00 am to 6:00 $\mathrm{pm}$-in our sample period-). ${ }^{14}$

Financial instruments are assumed to be liquid when admitted to trading on EuroTLX, but they may become illiquid afterwards. Should it happens, EuroTLX informs all direct members about liquidity conditions of the financial instrument. Also Borsa Italiana, on a monthly basis, provides the same information through a performance indicator available to the specialists operating on ExtraMOT. ${ }^{15}$ As pointed out later (Section 4), these institutional features may play a role in affecting the liquidity level of the trading venues.

Finally, between January 2010 and June 2013, the market rules of the trading platforms have been updated or modified rather frequently, as well as the technical infrastructure supporting trading activity. The most relevant episode has been the migration of trading from TradElect to Millennium electronic platform for all of Borsa Italiana cash markets in mid-2012. However, given that the majority of these changes occurred during the financial crisis, it is difficult to disentangle their impact on liquidity levels from the effect of market turbulences.

\section{The Italian dual-listed corporate bonds: the data set}

The analysis developed in the next two Sections focuses on 409 dual-listed corporate bonds over the period January 2010 - June 2013. Dual-listed bonds are securities traded across two venues: either DomesticMOT and EuroTLX, or ExtraMOT and EuroTLX (see Appendix 1 for more details on the sample). ${ }^{16}$ Venues pairs are identified by taking into account that a bond listed on DomesticMOT cannot be traded on ExtraMOT and vice versa. The sample period starts from January 2010 because the ExtraMOT segment was launched in the second half of 2009.

During the sample period, 100 bonds are traded across DomesticMOT and EuroTLX, while 309 securities are fragmented over ExtraMOT and EuroTLX (Table 1). Most of the bonds negotiated on DomesticMOT and EuroTLX are issued by banks (87\%), while the reverse holds for the securities negotiated on ExtraMOT and EuroTLX ( $66 \%$ of bonds issued by non-financial firms). ${ }^{17}$ In terms of trading volume, our sample is quite representative of the whole market, covering $37 \%$ of total trading for DomesticMOT, 95\% for ExtraMOT and 26\% for EuroTLX.

12 According to art. 2.2.2 of 2014 Market Rules (formerly art. 2.3.7 of TLX 2010 Market Rules), liquidity providers can operate as type-A market maker (with quote obligations for at least 250 securities already in 2010), or type-B market maker (currently with obligations for at least 30 securities), or as specialist. A specialist is a market member who undertakes to observe EuroTLX liquidity requirements solely with regard to (certificates and/or covered warrants and/or) bank bonds other than Eurobonds and/or other bonds: (i) issued by the same or by its controlled, controlling or affiliated company, or (ii) issued by other banking entities and placed by the Specialist or by its controlled, controlling or affiliated company among its clients or clients of such controlled, controlling or affiliated company or such company being part of the same banking group, or (iii) with regard to which any of the above mentioned entities committed itself vis-à-vis the issuer, other than a sovereign or a supranational entity or an agency, and/or vis-à-vis the intermediary to provide liquidity of the financial instrument in the secondary market. See definitions on TLX 2010 - 2013 Market Rules, in particular art. 3.32 for specific obligations/waivers and submission of bid offers only.

13 See art. 3.23 on TLX 2010 - 2013 Market Rules.

14 In 2010-2013, non-Eurobond bank bonds ended trading 30 minutes earlier (at 17:30). Currently (2014), continuous trading on EuroTLX takes place from 9:00 to 17:30.

15 The indicator is a weighted average of the percentage of time of compliance with respect to quote obligation and, as far as the assessment of the compliance to the requirements set by Borsa Italiana is concerned, should not fall below 90\%. See art. 14 of ExtraMOT Market Instructions (2010).

16 Such bonds can also be traded on other venues ruled out as they account for a marginal share of executed trade. 17 The sample included two bonds issued by insurance companies (we ruled them out). 
During the sample period, on average non-financial bonds show higher residual maturity than bank bonds in all trading venues both for the whole market and for our sample (Figure 1). In particular, at the market level, maturity ranges from 4.9 to 5.6 years for non-financial bonds (respectively, on EuroTLX and DomesticMOT), and from 2.8 to 4.4 years for bank securities (respectively, EuroTLX and DomesticMOT). At sample level, data show similar features. ${ }^{18}$

Table 1 - Corporate bond turnover by trading venue and issuer sector (January 2010 - June 2013; monetary values in million of euros)

\begin{tabular}{|c|c|c|c|c|c|c|c|c|}
\hline \multirow[t]{2}{*}{ market } & \multirow{2}{*}{$\begin{array}{l}\text { issuer } \\
\text { sector }\end{array}$} & \multicolumn{3}{|c|}{ whole market } & \multicolumn{4}{|l|}{ sample } \\
\hline & & $\mathrm{n}^{\circ}$ of bonds & turnover & weight & $\mathrm{n}^{\circ}$ of bonds & turnover & weight & $\begin{array}{c}\text { coverage of } \\
\text { market } \\
\text { turnover }\end{array}$ \\
\hline \multirow[t]{3}{*}{ DomesticMOT } & bank & 792 & 43.304 & $81.9 \%$ & 87 & 10.019 & $51.8 \%$ & $23.1 \%$ \\
\hline & $\begin{array}{l}\text { non- } \\
\text { financial }\end{array}$ & 18 & 9.581 & $18.1 \%$ & 13 & 9.334 & $48.2 \%$ & $97.4 \%$ \\
\hline & total & 810 & 52.885 & $100.0 \%$ & 100 & 19.353 & $100.0 \%$ & $36.6 \%$ \\
\hline \multirow[t]{3}{*}{ ExtraMOT } & bank & 109 & 4.926 & $44.9 \%$ & 104 & 4.833 & $46.4 \%$ & $98.1 \%$ \\
\hline & $\begin{array}{l}\text { non- } \\
\text { financial }\end{array}$ & 216 & 6.041 & $55.1 \%$ & 205 & 5.581 & $53.6 \%$ & $92.4 \%$ \\
\hline & total & 325 & 10.967 & $100.0 \%$ & 309 & 10.414 & $100.0 \%$ & $95.0 \%$ \\
\hline \multirow[t]{3}{*}{ EuroTLX } & bank & 4.635 & 136.898 & $81.0 \%$ & 191 & 23.133 & $53.5 \%$ & $16.9 \%$ \\
\hline & $\begin{array}{l}\text { non- } \\
\text { financial }\end{array}$ & 1.219 & 32.069 & $19.0 \%$ & 218 & 20.114 & $46.5 \%$ & $62.7 \%$ \\
\hline & total & 5.854 & 168.967 & $100.0 \%$ & 409 & 43.247 & $100.0 \%$ & $25.6 \%$ \\
\hline
\end{tabular}

Source: authors' elaboration on Consob internal database.

Figure 1 - Bond average residual maturity by trading venue and issuer sector (January 2010 - June 2013; market and sample figures)
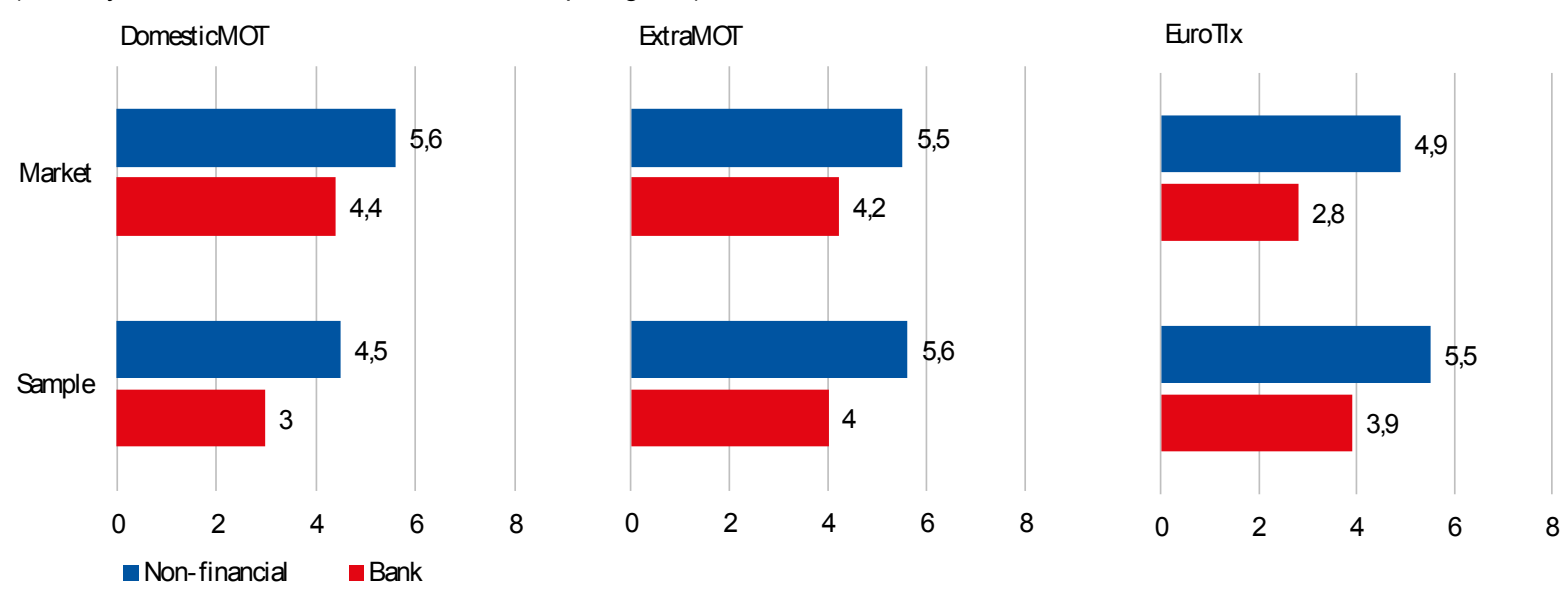

We also track data on minimum trading size (MTS), in order to test whether bonds exposed to retail trading (i.e. securities with MTS equal to 1,000 euros) are less frequently traded than bonds with higher MTS (typically 50,000 or 100,000 euros). When considering the whole market, bonds with 1,000 euros MTS represent more than $90 \%$ of total non-government bond turnover on DomesticMOT, $66 \%$ on EuroTLX, and $16 \%$ on ExtraMOT (Figure 2). Breaking these figures down by the issuer industry, bank bonds with 1,000 euros MTS account for $91 \%$ of total bank bonds

18 This evidence is also mirrored by the data on the maturity at issuance (available upon request). In particular, both at the market and at the sample level, maturity at issuance ranges from around 5 to 6 years for bank bonds (respectively, on EuroTLX and DomesticMOT), and from around 7 to almost 8 years for non-financial securities (respectively, DomesticMOT and ExtraMOT). 
turnover on DomesticMOT, 72\% on EuroTLX and 7\% ExtraMOT; for non-financial issuers these figures are equal, respectively, to $51 \%, 47 \%$ and $24 \%$. At the sample level, data exhibit a similar pattern, given that total turnover on DomesticMOT is almost entirely related to bonds with MTS equal to 1,000 euros, while bonds with a higher MTS capture a much larger share of trading volume on EuroTLX (30\%) and on ExtraMOT (83\%). Hence, data indicate a much greater presence of retail investors on DomesticMOT than on ExtraMOT and EuroTLX.

Figure 2 - Bond minimum trading size by trading venue and issuer sector (January 2010 - June 2013; market and sample figures in percentage of turnover)

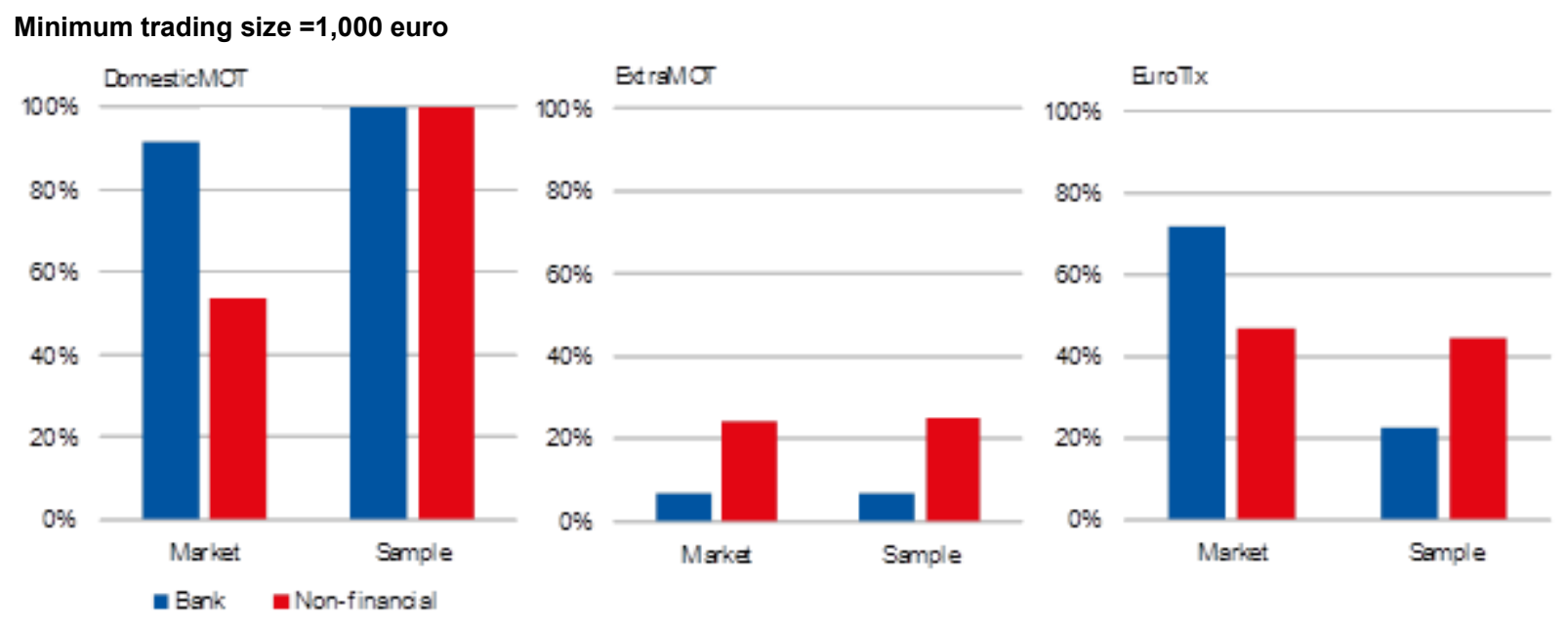

Breaking down the turnover by issuer nationality, sample statistics are overall consistent with whole market data, apart from bank bonds traded in DomesticMOT (in our sample, Italian securities are overweighed) and non-financial bonds traded in EuroTLX (in our sample, Italian securities are overweighed; Figure 3). ${ }^{19}$

Figure 3 - Bond issuer nationality by trading venue and issuer sector (January 2010 - June 2013; market and sample figures in percentage of turnover)

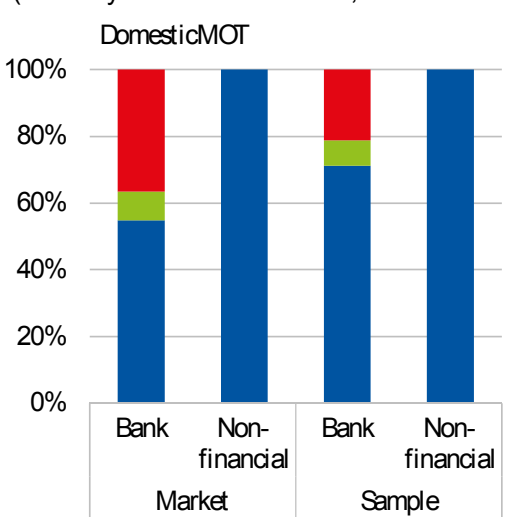

- Italy Eurozone ex Italy
ExtraMOT

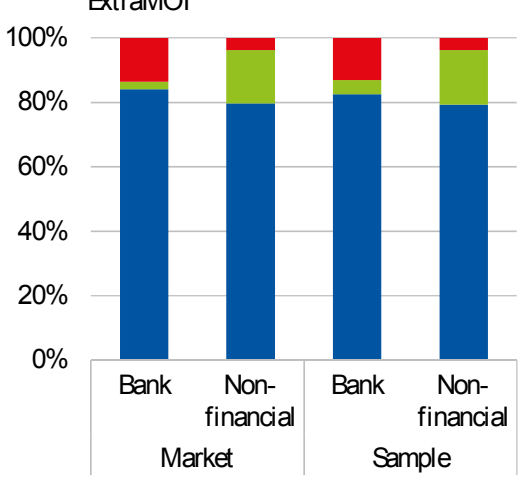

Extra 日MU

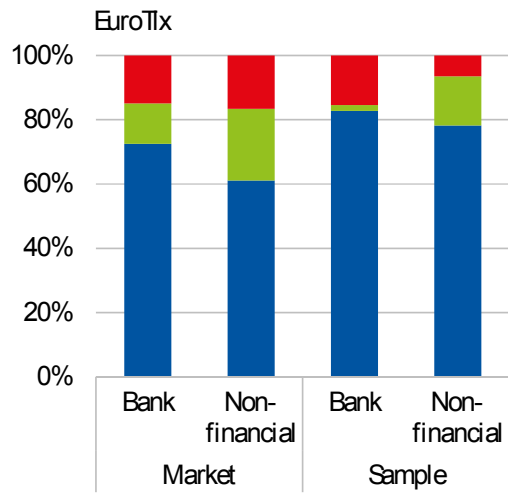

As far as the coupon structure is concerned, our sample tracks closely the whole market. On DomesticMOT, bank bonds are mainly represented by structured products ${ }^{20}(48 \%$ of bank bond turnover), followed by fixed $(30 \%)$ and floating $(22 \%)$ rate securities; whilst, fixed coupon bonds

19 For the identification of the issuer nationality, see Appendix 1.

20 Incorporating a derivative or stochastic component. 
predominate in the non-financial sector (Figure 4). Coupon structures look more conservative on ExtraMOT, since the turnover is mainly due to fixed rate coupon products $(98 \%$ for bank bonds and $83 \%$ for non-financial bonds respectively). On EuroTLX, fixed coupon bank bonds account for $47 \%$ of the turnover, followed by structured products $(37 \%)$, and floating rate bonds $(16 \%)$.

Figure 4 - Bond coupon structure by trading venues and issuer sector (January 2010 - June 2013; market and sample figures in percentage of turnover)
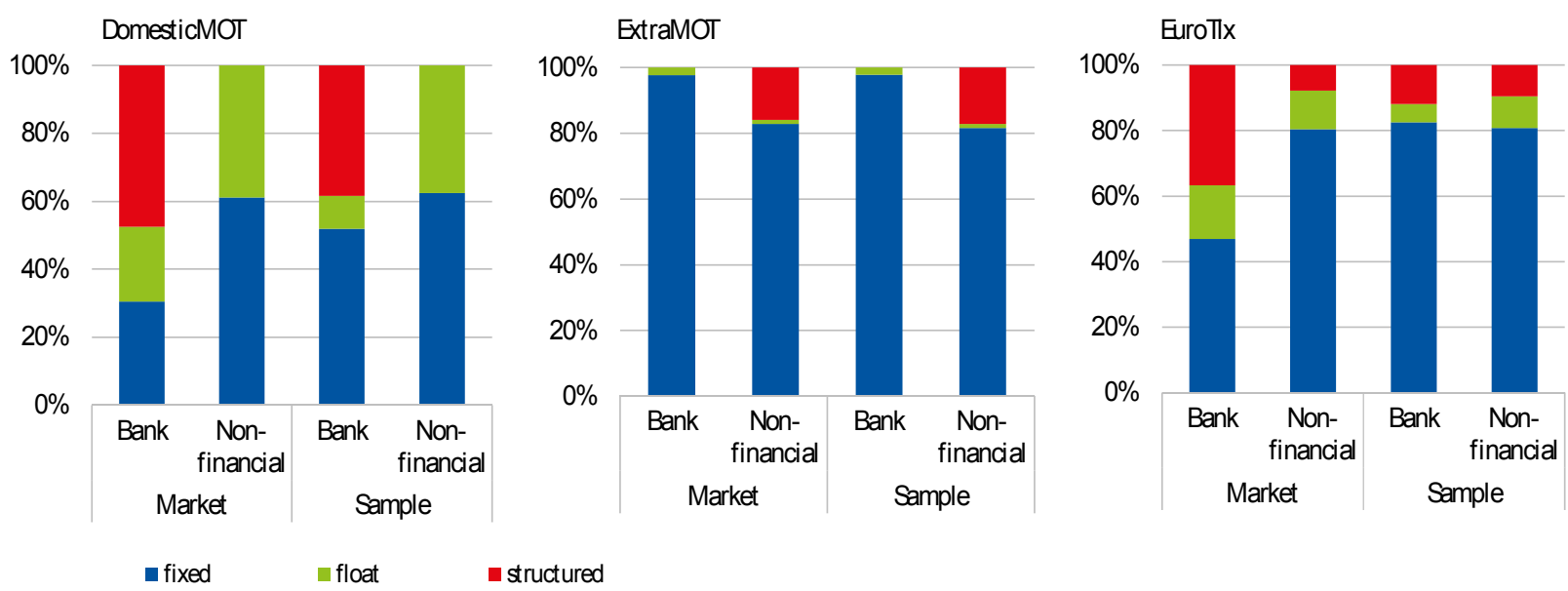

Finally, Figure 5 shows the distribution of bonds' trading volumes in our sample by official rating. The turnover of Top rated (A-AAA) bank bonds is significantly greater than the turnover of bonds with lower ratings a (B - BBB class) on both EuroTLX and ExtraMOT. On the contrary, B-BBB bonds show a higher turnover than top rated instruments on both EuroTLX and ExtraMOT. ${ }^{21}$ As for DomesticMOT, all sample issues but one, belonging to rated issuers (mainly primary banks), were found to be not rated individually.

Figure $\mathbf{5}$ - Dual-listed bonds by issue ratings, trading venues and issuer sector (January 2010 - June 2013; in percentage of turnover; number of bonds are reported)
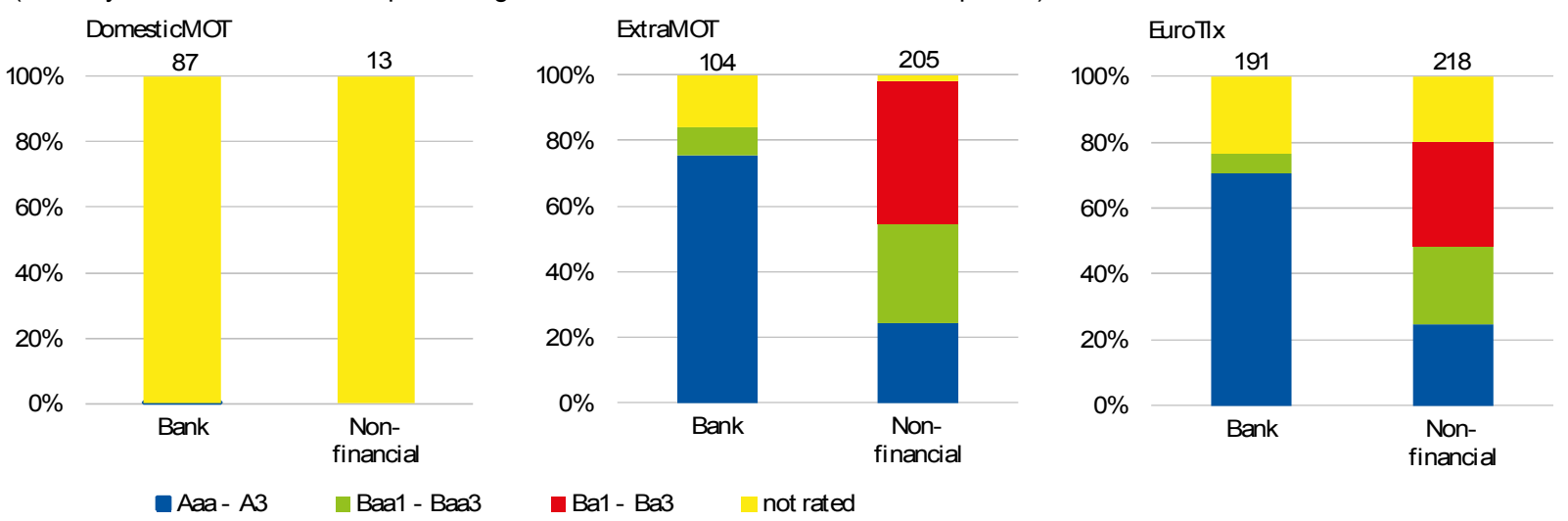

21 We refer to the rating released by Moody's. Overall, rated securities account for roughly $43 \%$ of the total turnover on EuroTLX and ExtraMOT, while B-BBB rated bonds represent respectively $37 \%$ and $51 \%$ of turnover on EuroTLX and ExtraMOT subsamples. 


\section{Liquidity of the Italian dual-listed corporate bonds}

When measuring liquidity ${ }^{22}$, academics and practitioners have long referred to three main concepts: depth, resiliency and tightness. Depth is related to the orders' size. Resiliency measures the price adjustments in response to a large order flows; so that it depends on the elasticity of supply and demand. Tightness proxies the trading costs incurred by investors in terms of immediacy, i.e. the costs associated to the time interval elapsing before incoming market orders are executed. Finally, a straight liquidity indicator is represented by trading frequency (number of trades per unit of time).

In this paper, we rely on four widely used liquidity indicators. First, in order to account for the depth of the order book we used the turnover ratio:

$$
\mathrm{V}_{\mathrm{t}}=\mathrm{V}_{i d}=\mathrm{p}_{i d} * \mathrm{TV}_{i d} / \mathrm{AOi}
$$

where $\mathrm{p}_{\mathrm{id}}$ and $\mathrm{TV}_{\mathrm{id}}$ are respectively the price and the traded volume of bond $i$ on day $d$; $\mathrm{AO}_{\mathrm{i}}$ is the outstanding amount of bond $i$. The deeper the order book, the higher the trading volume and, consequently, the turnover ratio. As argued by several authors (Alexander et al., 2000), low trading volume is important because it affects the inventory carrying costs of dealers, who pass them on to investors (as transaction costs). In response, investors command higher returns thus raising the cost of debt capital to issuers. However, as shown by empirical evidence on the US markets, trading volume and turnover ratio tends to rise with default risk, interest rate risk, and returns volatility, and therefore, when using trading volume as a proxy for liquidity, one needs to control also for these factors.

The standard measure for resiliency is the Amihud (2002) price impact indicator:

$$
\text { Illiq }_{\text {id }}=\frac{\left|\mathrm{r}_{\mathrm{id}}\right|}{\mathrm{TV}_{\mathrm{id}}}
$$

where $\mathrm{r}_{\mathrm{id}}$ is the return of bond $i$ on day $d$, while $\mathrm{TV}_{\mathrm{id}}$ is the daily volume of the same security on the same day. In a liquid market, large orders should not lead to significant price changes.

In order to capture tightness, we compute the Roll (1984) indicator which can be regarded as a proxy for the bid-ask spread; Roll suggests using twice the square root of the covariance between consecutive daily price changes $\left(\Delta \mathrm{p}_{\mathrm{t}}, \Delta \mathrm{p}_{\mathrm{t}-1}\right)$ :

$$
\mathrm{S}=2 \sqrt{-\operatorname{Cov}\left(\Delta \mathrm{p}_{\mathrm{t}}, \Delta \mathrm{p}_{\mathrm{t}-1}\right)}
$$

Finally, trading frequency is captured by a zero-trade day statistics:

$$
Z_{i}=\frac{N Z R_{i}}{T_{i}}
$$

22 For a discussion on liquidity measurement see Beber and Pagano (2008), Fleming (2003), Bao et al., (2008), Goyenko et al. (2009), Sarr and Lybek (2002), Lesmond et al. (1999), Hasbrouck (2004, 2009) and Lesmond (2005). Among the most recent contributions, based on the principal component analysis, see Nielsen et al. (2012), who obtain an efficient proxy of liquidity by using four indicators: Amihud (2002), implicit trading costs, turnover and zero-trade days proxies. In this work the choice of liquidity indicators has also been forced by data limitations. For instance, we could not compute measures based on the actual bid-ask spread since we do not have access to order data. 
where NZR is the number of days with no trades and $T_{i}$ is the total number of trading days in the sample period. ${ }^{23}$

\section{The liquidity of dual-listed bonds across trading venues}

We look at the liquidity levels of the dual-listed corporate bonds over the period January 1, 2010 June 30, 2013. A $t$-test on the difference between the means of the aforementioned indicators has been performed to check whether the liquidity of bonds in our sample is different across venues (Table 2). ${ }^{24}$ Then, for each trading venue we check whether liquidity differs between bank and nonfinancial bonds.

With the exception of non-financial bonds traded on DomesticMOT and EuroTLX that are frequently exchanged, Table 2 shows that all the other bonds trade quite infrequently, since the average zero-trade statistics ranges between $30 \%$ and $75 \%$ depending on the trading venue. ${ }^{25}$

Table 2 - Liquidity indicators of dual-listed bonds by trading venue and issuer sector (average percentage values over the period January 1, 2010 - June 30, 2013)

\section{DomesticMOT vs EuroTLX}

\begin{tabular}{|c|c|c|c|c|c|c|c|c|c|c|c|c|}
\hline \multirow[b]{2}{*}{ liquidity indicator } & \multicolumn{2}{|c|}{$\begin{array}{l}\text { whole sample } \\
(n=100)\end{array}$} & \multirow[b]{2}{*}{ Turnover } & \multirow[b]{2}{*}{$\begin{array}{l}\text { Zero- } \\
\text { trade }\end{array}$} & \multicolumn{3}{|c|}{$\begin{array}{l}\text { bank bonds subsample } \\
(n=87)\end{array}$} & \multirow[b]{2}{*}{$\begin{array}{l}\text { Zero- } \\
\text { trade }\end{array}$} & \multicolumn{4}{|c|}{$\begin{array}{l}\text { non-financial bonds subsample } \\
(\mathrm{n}=13)\end{array}$} \\
\hline & Amihud & Roll & & & Amihud & Roll & Turnover & & Amihud & Roll & Turnover & Zero-trade \\
\hline DomesticMOT (a) & $22.2 \%$ & $47.9 \%$ & $1.9 \%$ & $28.9 \%$ & $23.3 \%$ & $53.2 \%$ & $1.8 \%$ & $33.6 \%$ & $0.5 \%$ & $23.6 \%$ & $2.1 \%$ & $0.2 \%$ \\
\hline $\mathrm{TLX}(\mathrm{b})$ & $8.8 \%$ & $27.2 \%$ & $1.6 \%$ & $33.0 \%$ & $11.6 \%$ & $28.3 \%$ & $1.7 \%$ & $39.4 \%$ & $1.4 \%$ & $20.4 \%$ & $0.8 \%$ & $1.2 \%$ \\
\hline (a) - (b) significant ${ }^{1}$ & $\left({ }^{*}\right)$ & $\left({ }^{*}\right)$ & & & $\left({ }^{*}\right)$ & $\left({ }^{*}\right)$ & & & $\left({ }^{*}\right)$ & & $\left({ }^{*}\right)$ & $\left({ }^{*}\right)$ \\
\hline result & $\begin{array}{l}\text { TLX more } \\
\text { liquid }\end{array}$ & $\begin{array}{l}\text { TLX more } \\
\text { liquid }\end{array}$ & $\begin{array}{l}\text { same } \\
\text { liquidity }\end{array}$ & $\begin{array}{l}\text { same } \\
\text { liquidity }\end{array}$ & $\begin{array}{l}\text { TLX more } \\
\text { liquid }\end{array}$ & $\begin{array}{l}\text { TLX more } \\
\text { liquid }\end{array}$ & $\begin{array}{l}\text { same } \\
\text { liquidity }\end{array}$ & $\begin{array}{l}\text { same } \\
\text { liquidity }\end{array}$ & $\begin{array}{l}\text { MOT } \\
\text { more } \\
\text { liquid }\end{array}$ & $\begin{array}{l}\text { same } \\
\text { liquidity }\end{array}$ & $\begin{array}{l}\text { MOT } \\
\text { more } \\
\text { liquid }\end{array}$ & $\begin{array}{l}\text { MOT } \\
\text { more } \\
\text { liquid }\end{array}$ \\
\hline
\end{tabular}

\section{ExtraMOT vs EuroTLX}

\begin{tabular}{|c|c|c|c|c|c|c|c|c|c|c|c|c|}
\hline \multirow[b]{2}{*}{ liquidity indicator } & \multicolumn{2}{|c|}{$\begin{array}{l}\text { whole sample } \\
(n=309)\end{array}$} & \multirow[b]{2}{*}{ Turnover } & \multirow[b]{2}{*}{$\begin{array}{l}\text { Zero- } \\
\text { trade }\end{array}$} & \multicolumn{3}{|c|}{$\begin{array}{l}\text { bank bonds subsample } \\
(\mathrm{n}=104)\end{array}$} & \multirow[b]{2}{*}{$\begin{array}{l}\text { Zero- } \\
\text { trade }\end{array}$} & \multicolumn{4}{|c|}{$\begin{array}{l}\text { non-financial bonds subsample } \\
(n=205)\end{array}$} \\
\hline & Amihud & Roll & & & Amihud & Roll & Turnover & & Amihud & Roll & Turnover & Zero-trade \\
\hline ExtraMOT (a) & $28.9 \%$ & $16.6 \%$ & $0.1 \%$ & $73.8 \%$ & $16.3 \%$ & $16.5 \%$ & $0.2 \%$ & $71.3 \%$ & $35.8 \%$ & $16.7 \%$ & $0.1 \%$ & $75.0 \%$ \\
\hline $\mathrm{TLX}(\mathrm{b})$ & $6.3 \%$ & $25.1 \%$ & $0.4 \%$ & $48.1 \%$ & $4.4 \%$ & $26.7 \%$ & $0.7 \%$ & $43.5 \%$ & $7.3 \%$ & $24.3 \%$ & $0.3 \%$ & $50.4 \%$ \\
\hline (a) - (b) significant ${ }^{1}$ & $\left({ }^{*}\right)$ & & $\left({ }^{*}\right)$ & $\left({ }^{*}\right)$ & $\left({ }^{*}\right)$ & $\left({ }^{*}\right)$ & $\left({ }^{*}\right)$ & $\left({ }^{*}\right)$ & $\left({ }^{*}\right)$ & $\left({ }^{*}\right)$ & $\left({ }^{*}\right)$ & $\left({ }^{*}\right)$ \\
\hline result & $\begin{array}{l}\text { TLX more } \\
\text { liquid }\end{array}$ & $\begin{array}{l}\text { same } \\
\text { liquidity }\end{array}$ & $\begin{array}{l}\text { TLX more } \\
\text { liquid }\end{array}$ & $\begin{array}{l}\text { TLX more } \\
\text { liquid }\end{array}$ & $\begin{array}{l}\text { TLX more } \\
\text { liquid }\end{array}$ & $\begin{array}{l}\text { ExtraMOT } \\
\text { more } \\
\text { liquid }\end{array}$ & $\begin{array}{l}\text { TLX more } \\
\text { liquid }\end{array}$ & $\begin{array}{l}\text { TLX more } \\
\text { liquid }\end{array}$ & $\begin{array}{l}\text { TLX more } \\
\text { liquid }\end{array}$ & $\begin{array}{l}\text { ExtraMOT } \\
\text { more } \\
\text { liquid }\end{array}$ & $\begin{array}{l}\text { TLX more } \\
\text { liquid }\end{array}$ & $\begin{array}{l}\text { TLX more } \\
\text { liquid }\end{array}$ \\
\hline
\end{tabular}

Source: our elaborations on Consob database. ${ }^{1}$ Sample average of the liquidity indicators computed on monthly data and in percentage values. $\mathrm{N}=$ number of bonds dual-listed on each pair of trading venues. $\left({ }^{*}\right)=$ Null hypothesis rejected at $95 \%$ confidence level. Higher values for Amihud, Roll, zero-trade indicators mean lower liquidity levels.

23 For all the indicators, we took the monthly averages of the daily measures within the sample period. Except for the turnover ratio, they should be interpreted as illiquidity indicators, i.e. liquidity decreases as they increase.

24 As a robustness check we performed both an independent and a dependent sample $t$-test. The $t$-test has been performed also on a monthly basis, with results similar to those reported in Appendix 3.

25 On DomesticMOT the monthly average of zero-trade rises from 36\% in 2010 to $46 \%$ at the end of June 2013 (in 2010 the average number of no-trading days over a month was almost 8, while it became 10 at the end of June 2013). On EuroTLX, the zero-trade indicator goes from about $18 \%$ in 2010 to $68 \%$ in the first half of 2013 (over the sample period the average number of no trading days on EuroTLX rose from 4 to 15). As for dual-listed bonds traded across ExtraMOT and EuroTLX, during the sample period the percentage of days with no trade in a month is permanently higher on ExtraMOT (both for bank and for non-financial bonds); while, on EuroTLX zero-trade increased from $20 \%$ to more than $50 \%$ for bank bonds and from $30 \%$ to $70 \%$ for non-financial securities. 
Basically, both the zero-trade indicator and the turnover ratio suggest that liquidity of dual-listed bonds is not significantly different between DomesticMOT and EuroTLX; while, liquidity is higher on EuroTLX when measured by both the Amihud and the Roll statistics. Similar evidence holds also for the subsample of bank bonds. For non-financial securities, instead, three out of four liquidity measures suggest liquidity being higher on DomesticMOT than on EuroTLX. The Roll indicator is not significantly different across the two venues ${ }^{26}$. The time series evolution of the liquidity indicator is reported in Figure 6 (monthly average liquidity levels by venue and sector over the sample time period). ${ }^{27}$

For each trading venue, we also check whether liquidity differs significantly between bank bonds and non-financial corporate bonds, through a t-test for the significance of the difference between the means. Over the sample period, liquidity as measured by Amihud, Roll and zero-trade statistics turns out to be always significantly different across bank and non-financial bonds (while the evidence is less clear-cut for the turnover ratio), being the former less liquid than the latter.

Although with different intensity, liquidity conditions deteriorated on both trading venues both in the second half of 2011 (when the sovereign debt crisis reached its peak) and in the first half of 2012 (when market turbulences revived).

Taking the sub-sample of bonds traded on ExtraMOT and EuroTLX, we find that the former venue is basically less liquid than the latter; contrarian evidence is supported by the Roll indicator only. This might be partly due to the fact that the presence of a liquidity provider is optional on ExtraMOT, whereas it is compulsory on EuroTLX, as discussed in Section 2. Moreover, bank bonds are more liquid than non-financial securities according to all indicators except for Roll. Figure 7 shows that during the sovereign debt crisis, bank bonds traded on DomesticMOT and EuroTLX experienced a significant liquidity deterioration; at the end of June 2013 liquidity levels were still lower than in 2010.

Difference in liquidity of dual-listed bonds should be driven essentially by differences in the microstructure of the trading venues. To gain some insight on this, we carried out a descriptive analysis of liquidity with respect to venues, controlling for four bonds' characteristics, i.e. the minimum trading size (MTS), issuer's nationality, coupon complexity and issuer's industry sector. $^{28} \mathrm{We}$ find that bonds features may impact differently on liquidity depending on the trading venue, thus suggesting that the way microstructural differences influence liquidity is not straightforward and relates to bonds attributes as well.

26 As for the t-test performed on a monthly basis, the Roll indicator would point to higher liquidity on DomesticMOT, although discontinuously.

27 This evidence has to be interpreted cautiously since it refers to a very small sample (13 bonds; left hand side graphs). However, as already shown in Table 3, such sample accounts for more than $70 \%$ of the non-financial bonds listed on DomesticMOT and for more than $97 \%$ of the turnover of the whole market segment.

28 We also investigated the relationship between liquidity levels and issue size. However, because of the low variability in this attribute (since all bonds in our sample have a quite small issue size), no clear pattern was found. 
Figure 6 - Average liquidity levels of dual-listed bonds on DomesticMOT and EuroTLX (monthly averages; percentage values)

\section{Zero-trade}
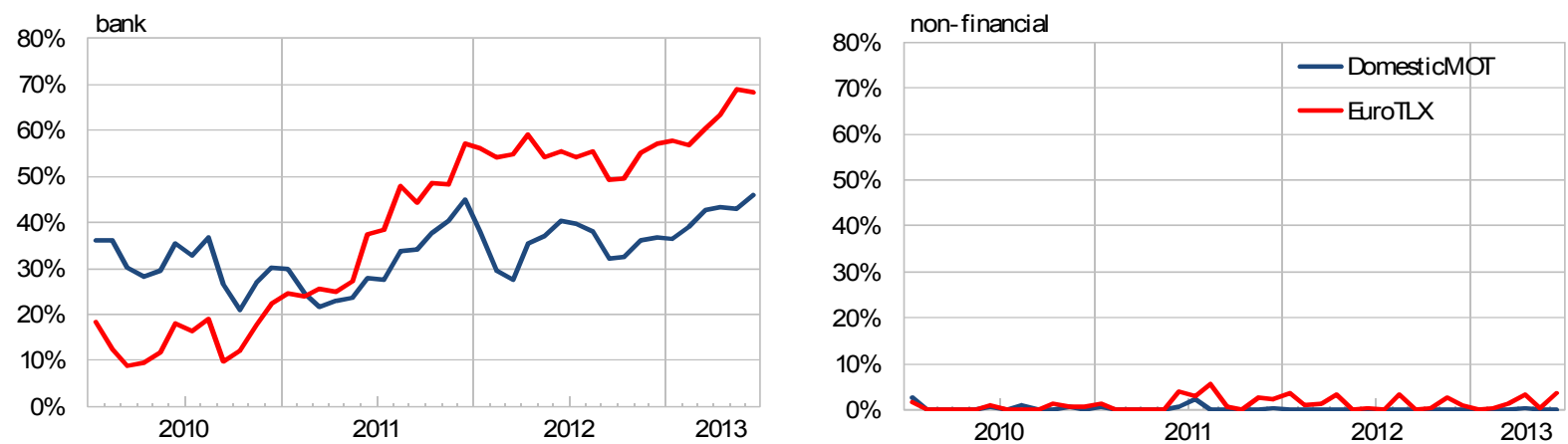

Turnover ratio

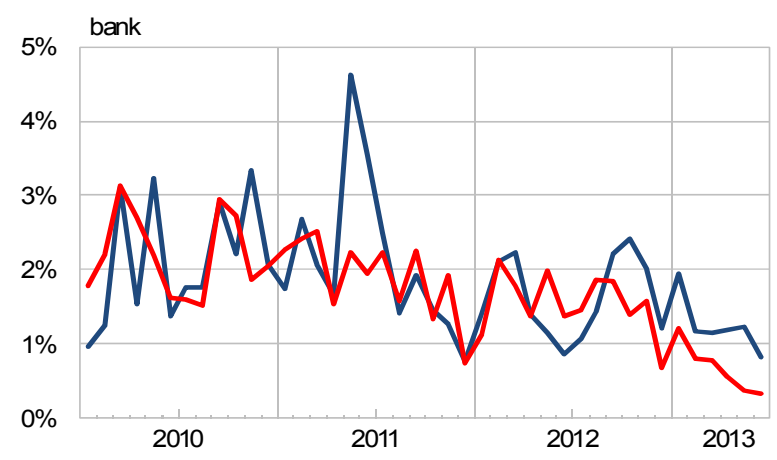

Amihud ratio
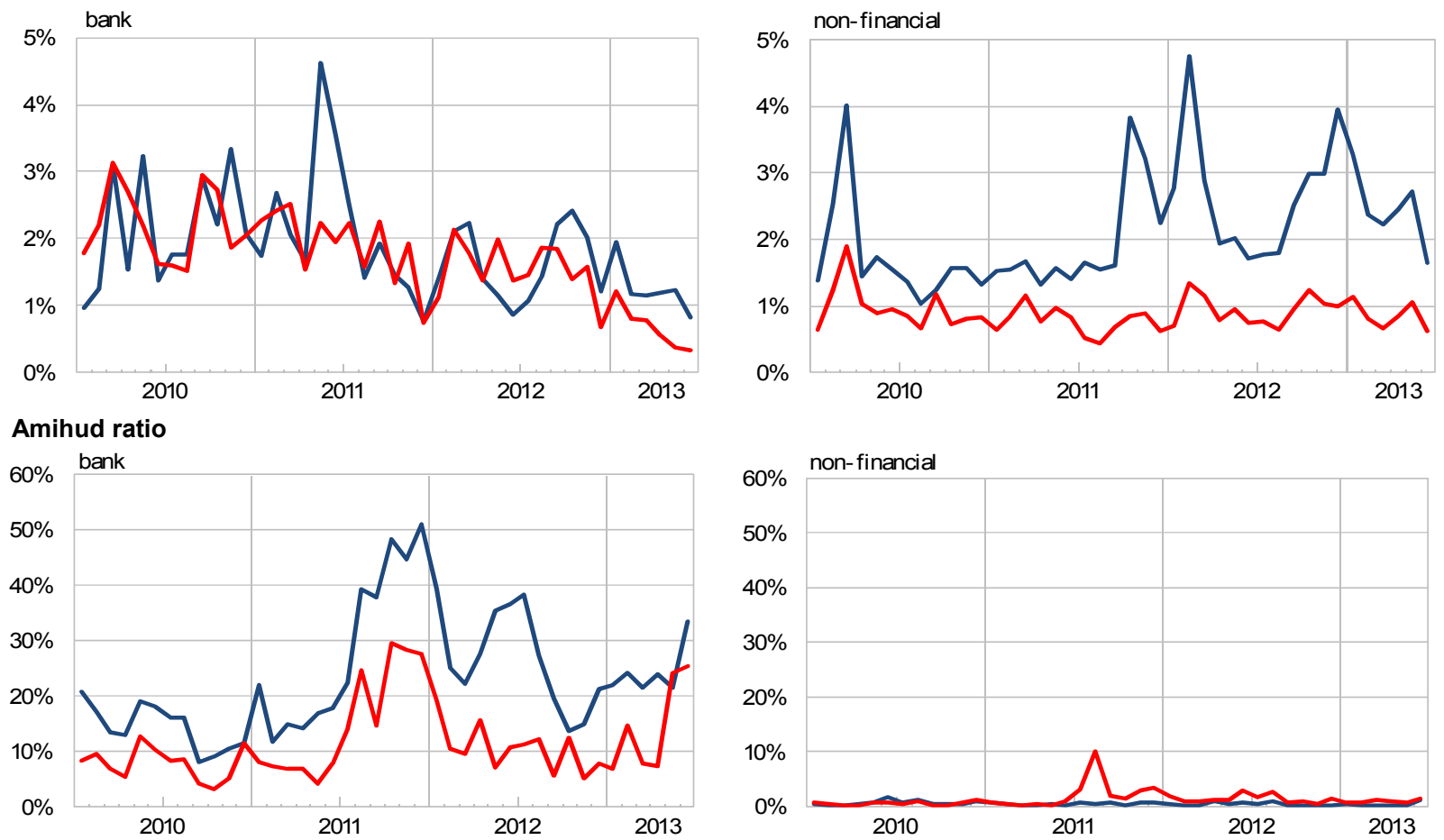

Roll indicator
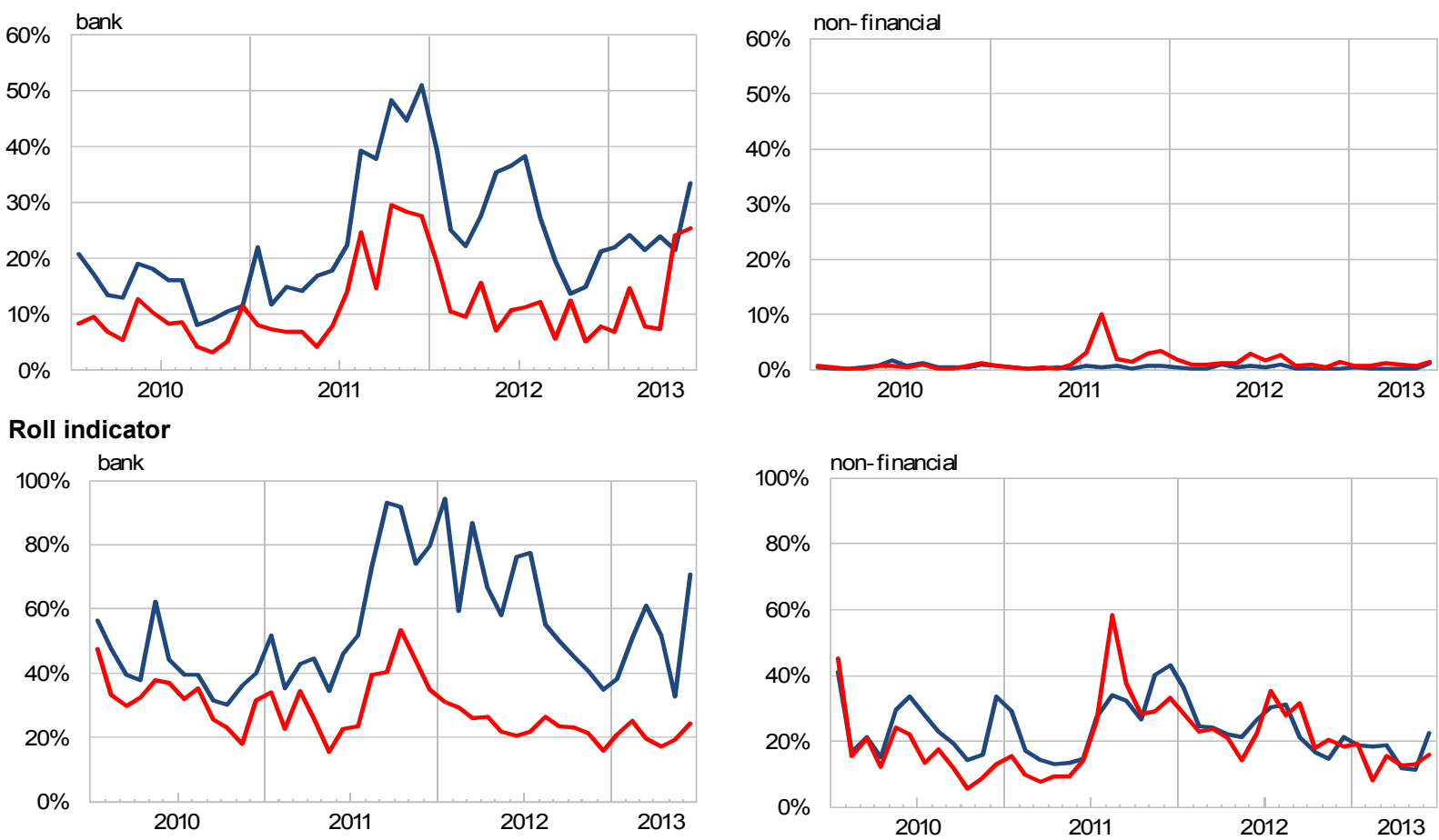

Source: our elaborations on CONSOB internal database on trading data. Indicators reported in the left graphs are calculated on a sample including 87 bank bonds traded across DomesticMOT and EuroTLX, while the indicators reported in the right graphs are computed on a sample including 13 non-financial bonds traded across DomesticMOT and EuroTLX. 
Figure 7 - Average liquidity levels of dual-listed bonds on ExtraMOT and EuroTLX (monthly averages; percentage values)

\section{Zero-trade}
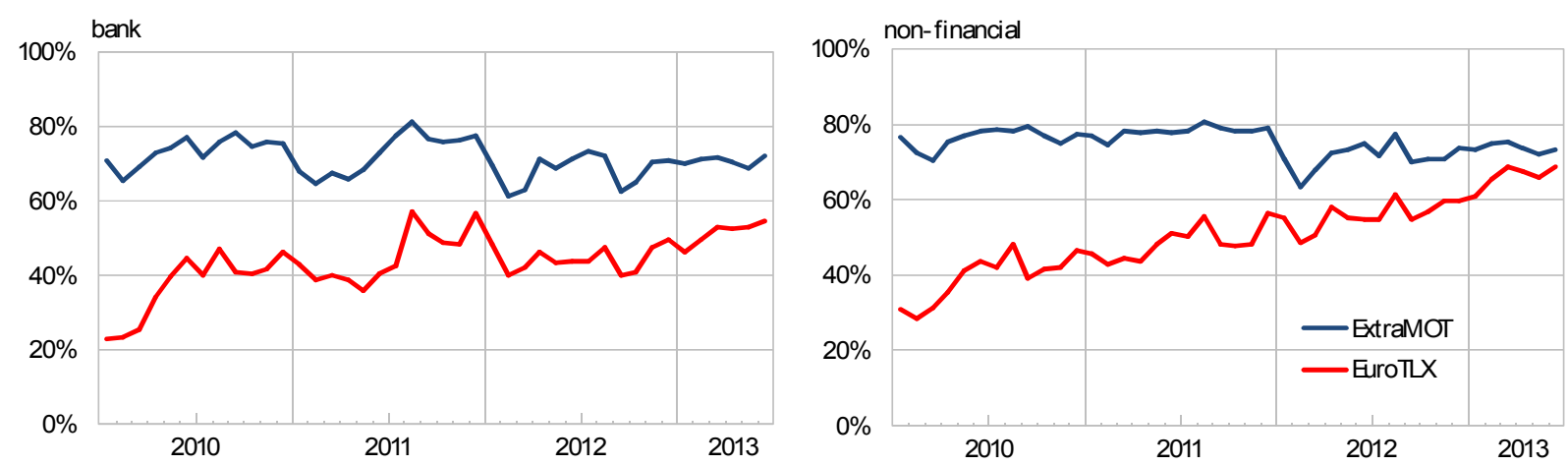

Turnover ratio
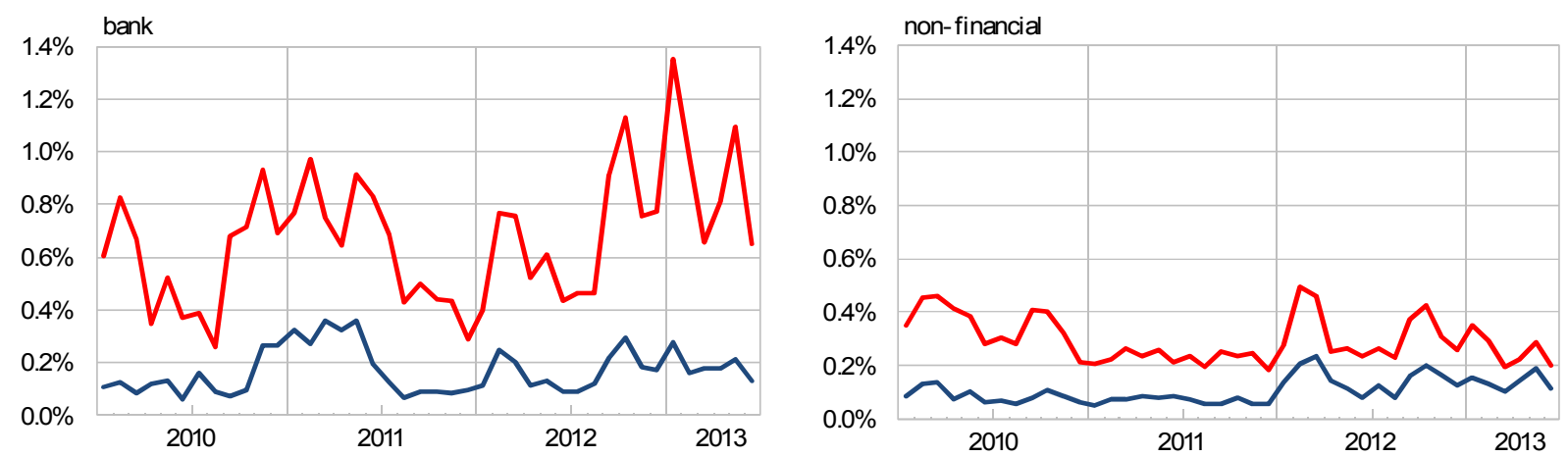

\section{Amihud ratio}

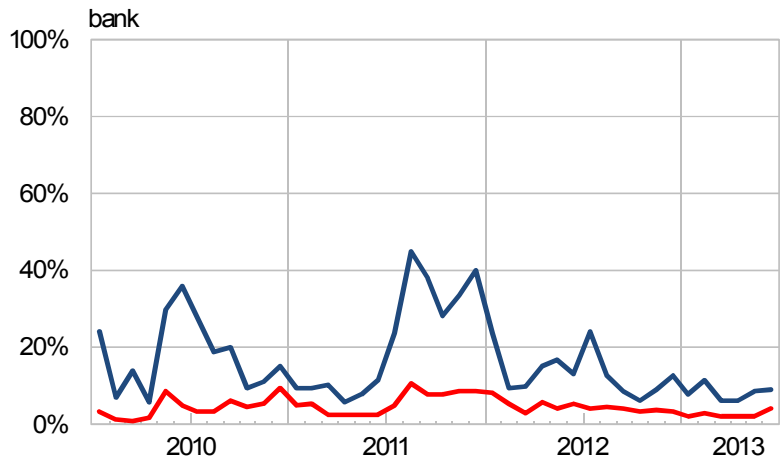

Roll indicator
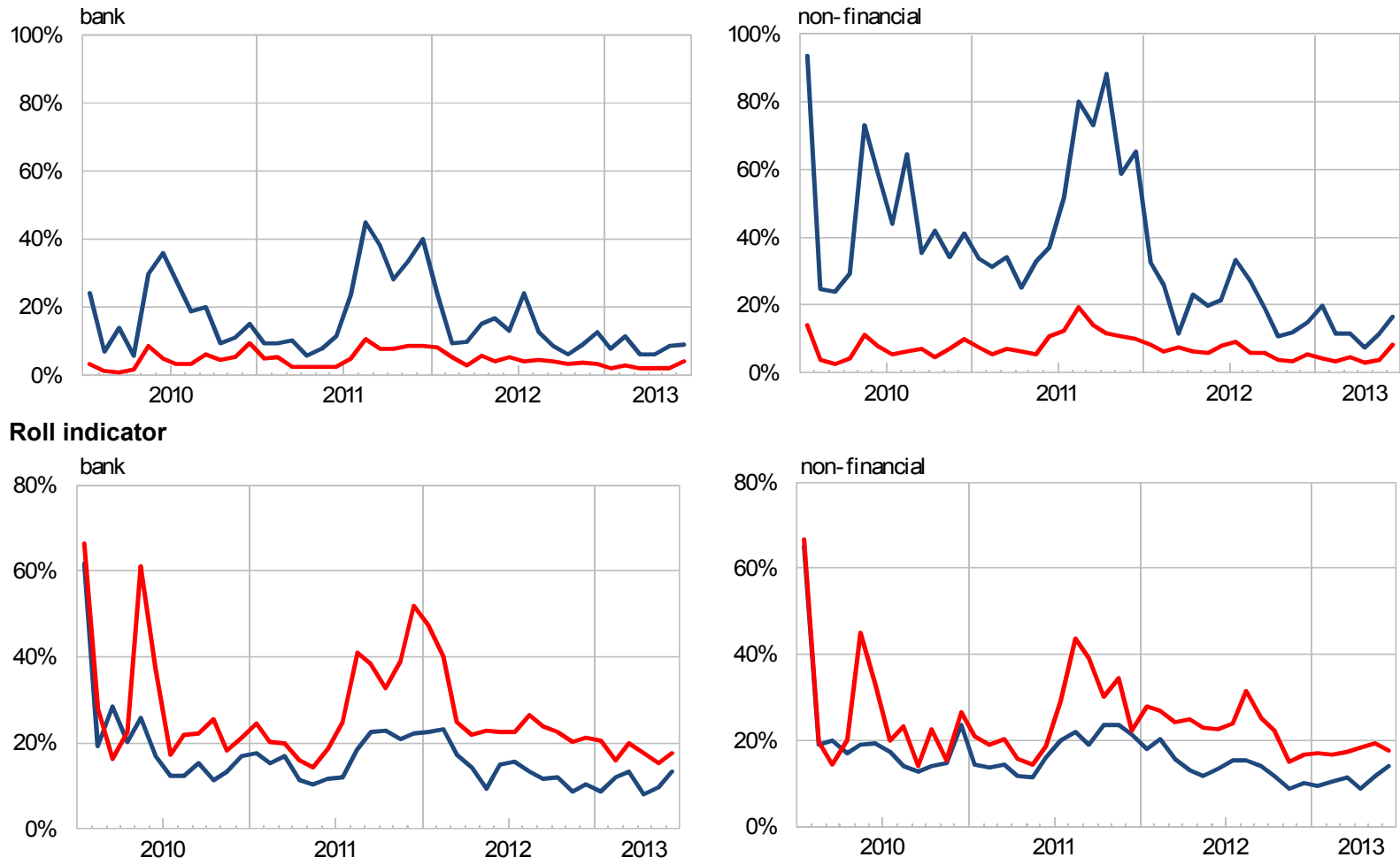

Source: our elaborations on CONSOB internal database on trading data. Indicators reported in the left graphs are calculated on a sample including 104 bank bonds traded across ExtraMOT and EuroTLX, while the indicators reported in the right graphs are computed on a sample including 205 non-financial bonds traded across ExtraMOT and EuroTLX. 
As for MTS, since almost all bonds fragmented across DomesticMOT and EuroTLX have MTS equal to 1,000 euro (so called retail bonds), the analysis will focus only on bonds traded across EuroTLX and ExtraMOT.

Using a t-test for the means, we test whether the liquidity differs across trading venues, controlling for issuer's industry sector and MTS. On average, as expected, a higher MTS is associated with better liquidity. Both the Amihud statistics and the turnover ratio suggest both financial and nonfinancial bonds with greater lot size (MTS > 1,000 euros) being more liquid. Such evidence implies that retail bonds have always a higher price impact indicator. The Roll bid-ask spread and the zerotrade statistics (roughly) support the evidence of similar liquidity conditions in spite of the minimum lot size. (Appendix 2, Table a2.1).

As for securities traded on both DomesticMOT and ExtraMOT, with the only exception of nonfinancial bonds traded on EuroTLX, the $t$-test for the mean provides clear-cut evidence that bonds issued by Italian companies are characterized by better liquidity levels; just the Roll spread sometimes captures similar liquidity levels (Appendix 2, Table a2.2, top panel). This evidence may eventually raise the issue of home-country bias.

Moreover, as for securities traded on both ExtraMOT and EuroTLX, Italian bonds are almost always significantly more liquid than foreign bonds on both venues. ${ }^{29}$ Overall, domestic bonds seem to be more liquid than the foreign securities with respect to almost all the liquidity indicators and especially to the zero-trade index (Appendix 2, Table a2.2, bottom panel; if not otherwise specified, Table sections without available data are omitted). ${ }^{30}$

Finally, as for coupon complexity, on average bank plain vanilla bonds traded on DomesticMOT and EuroTLX are more liquid than structured bonds on DomesticMOT when turnover ratio and zero-trade are used. However, the same securities compare differently on EuroTLX, with structured bonds being more liquid than plain ones with respect to all indicators except for the zero-trade (Appendix 2, Table a2.3). On ExtraMOT and EuroTLX, simple non-financial bonds are almost always less liquid than complex coupon bonds. Complexity and liquidity may be related because of investors' risk perception; on the one hand, uncertainty and (unanticipated) adverse shocks may affect complex products more heavily than plain ones; on the other hand, expectations of new economic and financial conditions call for hedging strategies to face incoming risks (since it may change the probability structure adopted to weight future states of the world.

In summary, while higher MTS is on average related to higher liquidity irrespective of the trading venues, other bond features such as issuer's industry sector and coupon complexity may impact differently on liquidity depending on the trading venues. This may well be related to differences in the microstructure of the trading venues. In this respect, and with specific reference to ExtraMOT and EuroTLX, two elements need to be taken into account: first, EuroTLX rule stating that at least one liquidity provider must be present for each listed financial instrument; second, the stricter

29 When comparing the values of each liquidity indicator across ExtraMOT and EuroTLX, the liquidity indicators perform much better on the latter for both bank and non-financial bonds, independently of nationality (again, this is in line with the evidence commented with respect to the whole sample; results available upon request to the authors).

$30 \mathrm{We}$ performed also a t-test comparing the values of each liquidity indicator across the two venues (results available upon request). Italian bank bonds are more liquid on DomesticMOT when considering the Amihud and turnover ratio statistics, while Italian non-financial bonds are always more liquid on DomesticMOT except for the Roll indicator (which points to the same level of liquidity). Foreign bank bonds are characterized by similar values of zero-trade days and turnover ratio across venues, while price resiliency and round trip costs seem to be lower on EuroTLX. 
requirements envisaged for the compliance to liquidity provider's obligations envisaged by EuroTLX relative to ExtraMOT (and DomesticMOT as well) ${ }^{31}$.

Figure 8 - Aggregate illiquidity indicators stemming from principal component analysis
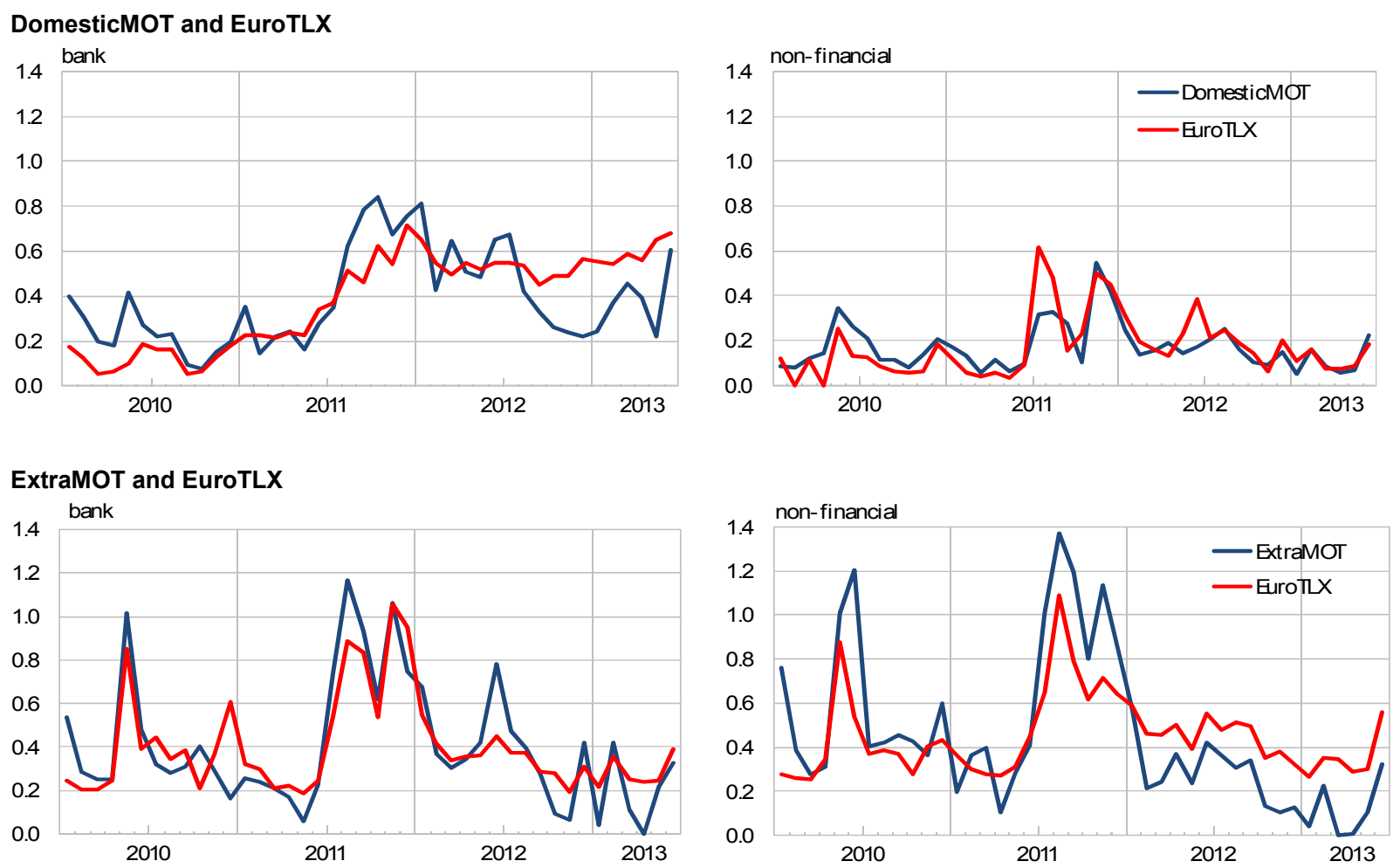

Note: the figure reports the normalized absolute value of the factor loading obtained by estimating the first principal component of four liquidity measures (percentage of days with zero-trade, price impact, turnover ratio and Roll indicator of bid-ask spread).

The evidence discussed so far is confirmed by the result of the principal component analysis (PCA), combining the four liquidity indicators $\left(\mathrm{m}_{\mathrm{k}}\right)$ into an aggregate (il)liquidity index (AII).

As expected, for all the trading venues, the AII achieves its peak during the sovereign debt crisis (from July 2011 to January 2012). However, liquidity deterioration of both bank and non-financial bonds has been more severe for bond traded on both ExtraMOT and EuroTLX than for bonds fragmented across DomesticMOT and EuroTLX (Figure 8).

Finally, we check how the four liquidity indicators contribute to AII by ranking the factor loadings of the first principal component:

$$
\mathrm{AII}_{\mathrm{t}}=\sum_{\mathrm{k}=1}^{4} \mathrm{w}_{\mathrm{k}} * \mathrm{~m}_{\mathrm{it}}^{\mathrm{k}}
$$

where $w_{k}$ are the factor loadings for the principal components. High factor loadings imply great importance of the corresponding indicators as a liquidity driver in each trading venue.

31 Regarding microstructural issues, it might be observed that, in general, a market operator has to strike a balance between the goal of attracting as many traders as possible (improving liquidity to maximize turnover and its revenues) and the cost of providing the level of liquidity associated with its expected profit. Therefore, a relatively new market entrant (such as EuroTLX) might have chosen to apply a more stringent (although slightly more expensive) liquidity requirements set in order to challenge the market share of the incumbent market operator. 
Figure 9 - Weights of liquidity indicators estimated by applying principal component analysis
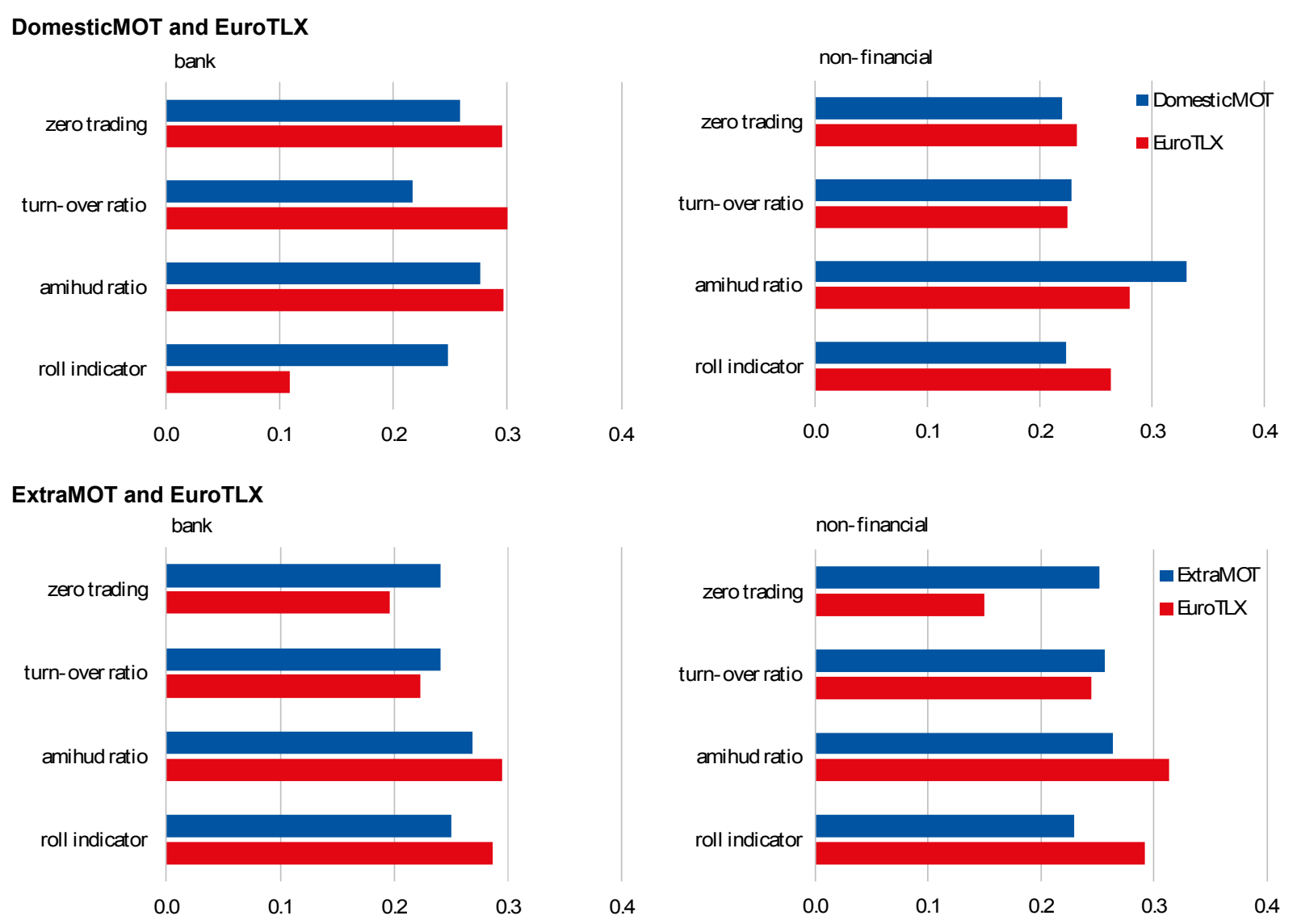

Note: the figure reports the normalized absolute value of the factor loading obtained by estimating the first principal component of the selected liquidity indicators (depth, frequency of trades, price resiliency and roundtrip costs).

As shown in Figure 9, the contribution of the four liquidity indicators to the AII is quite homogeneous across trading venues and across industries. Therefore, there is no evidence of a dominant single indicator acting as the key liquidity driver. Over the sample period, summarizing liquidity conditions of dual-listed bonds by a single indicator would thus be misleading; however, at some point in time, some liquidity dimensions may play a slightly more relevant role. ${ }^{32}$

\section{The determinants of trading across venues: empirical evidence for the Italian dual-listed corporate bonds}

This Section discusses the results of the econometric analysis regarding the determinants of trading occurrence (defined as the probability of trading) for the 409 bonds in our sample. This approach builds on the evidence highlighted in the previous Sections that infrequent trading is a key feature of Italian corporate bonds. ${ }^{33}$ Since all four liquidity indicators are informative about the liquidity of dual-listed bonds, we specified alternative models using some liquidity measures as dependent

32 As for bonds traded across ExtraMOT and EuroTLX, liquidity is evenly driven by the four liquidity indicators on ExtraMOT, while on EuroTLX the Amihud and Roll indicators tend to be slightly more relevant. The contribution of the four indicators to the AII is quite homogeneous also for bonds traded across DomesticMOT and EuroTLX, although for bank bonds on EuroTLX the Roll indicator appears to contribute less to liquidity, while on DomesticMOT the Amihud ratio contributes slightly more to the liquidity of non-financial bonds.

33 The only exception is given by non-financial bonds traded simultaneously on DomesticMOT and EuroTLX. 
variables. Results ${ }^{34}$ are qualitatively similar to those stemming from the trade occurrence model (we just report the evidence referring to trade occurrence though).

We thus test whether, and to what extent, a set of bond attributes and other variables impact differently on the probability of trade occurrence depending on the trading venue. Before going through the empirical evidence, we report a brief survey of the literature, which inspired us in the variables selection process.

\subsection{The determinants of corporate bond liquidity: a survey of the literature}

The empirical analysis of bond liquidity on secondary markets has ascertained the role of bond characteristics, issuer attributes, and market conditions. Although most of the studies focused on the US markets, a bunch of contributions analysed data on euro-denominated bonds (Annaert and De Ceuster, 1999; McGinty, 2001; Dìaz and Navarro, 2002; Houweling et al., 2005; Petrella and Resti, 2013).

Among the bond features, issue size is found to affect liquidity positively (Alexander et al., 2000; Hong and Warga, 2000; Hotchkiss and Jostova, 2007; Petrella and Resti, 2013). This result is consistent with the market microstructure inventory models (transaction costs associated with large issues are low because dealers may easily manage their inventory costs). Another rationalization hinges on the low-information-costs argument (large issues have less information costs, since more information is disseminated among investors and more investors own and analyze them). In addition, smaller issues are more easily absorbed by buy-and-hold investors who reduce trading and, hence, liquidity (see Houweling et al., 2005, for references on these views). However, some contrarian evidence is provided by McGinty (2001) who finds that the issued amount has a negative impact on liquidity.

Residual maturity has a positive impact on liquidity. Bonds tend to trade actively in the period immediately after the issuance, while liquidity drops after a few months, either because bonds tend to be seized in buy-and-hold portfolios (Sarig and Warga, 1989) or because managers are committed to make market prevalently in newly issued bonds (McGinty, 2001). Therefore trading volume decreases as residual maturity declines (Alexander et al., 2000; Hotchkiss and Jostova, 2007; Petrella and Resti, 2013); in addition, evidence shows that short residual maturity causes the bid-ask spread to increase (Warga, 1992; Hong and Warga, 2000; Houweling et al., 2005). ${ }^{35}$

There is an inverse correlation between rating and turnover (the worse the rating, the higher the turnover), thus reflecting a speculative component of trading. Moreover, securities with high ex ante credit risk are more subject to speculation because of likely future downgrades, which, in turn, intensifies trading (Alexander et al., 2000; Hotchkiss and Jostova, 2007; Petrella and Resti, 2013).

Also interest rate risk (either duration or, sometimes, time-to-maturity itself) may affect liquidity. However, the evidence is not conclusive on this point. ${ }^{36}$ For instance, Alexander et al. (2000) find weak evidence of a positive effect on volume; while, Petrella and Resti (2013) find a strong

34 Available upon request.

35 When the sample analyzed does not include newly issued bonds, some researchers define a threshold to mark old and young bonds: Alexander et al. (2000) used two years; Elton et al. (2002), Houweling et al., 2005 and Petrella and Resti (2013) one year; Ericson and Renault (2001) three months.

36 The interest rate risk is also captured the Fama-French slope factor, defined as the difference between the long term Treasury bond return and the one month Treasury rate at the end of the previous period (Houweling et al., 2005). 
significant relationship. Hotchkiss and Jostova (2007) point out mixed results, depending on the rating and the coupon structure. ${ }^{37}$

Yield dispersion (so called information risk), a measure of market participants' agreement on the value of a bond, is a further factor that induces speculative trading thus affecting liquidity (Houweling et al., 2005; Hotchkiss and Jostova, 2007; Alexander et al., 2000).

Among the issuers' attributes, empirical studies have also considered whether companies have publicly traded equity. Under the hypothesis that private firms convey less information to the market, the consequent adverse selection costs should negatively affect the liquidity of their debt. However, the evidence is not clear-cut, being either weak (Fenn, 2000) or in contrast with this hypothesis (Alexander et al., 2000). Issuer's industry may also be relevant, since it reflects both structural differences in industry regulation and (or) market trends.

Several authors investigate the correlation between bond and equity markets. Common factors such as firm specific news are expected to drive joint reactions of returns and volumes of bonds and stocks (Hotchkiss and Ronen, 2002; Hotchkiss and Jostova, 2007). De Jong and Driessen (2006) show that the liquidity of non-financial bond is related to the liquidity of government bonds.

Market conditions affects assets' liquidity that may change over time, especially during stress times. Estimate a market liquidity model represents a conventional way to capture the sensitivity of a given security to aggregate market liquidity conditions. It allows to distinguish the so-called systematic liquidity risk ${ }^{38}$ from the idiosyncratic one. The impact of market stress on bonds' liquidity has also been estimated by taking into account the impact of global risk aversion, usually proxied by the so-called quality spread, i.e. the spread between BBB and AAA non-financial bonds' returns (Petrella and Resti, 2013). The reaction to financial stress of low and high-yield bonds may differ since yields on BBB-rated issues tend to rise much more than AAA-rated ones, widening the gap between them. Another proxy of market stress conditions is the spread between the rate at which banks can access central bank funding and a risk-free rate (i.e. the Ted spread for the US market or the Euribor-OIS spread for the European markets).

\subsection{The model specification}

In order to investigate the determinants of trade occurrence, we estimate a random effect panel logit model ${ }^{39}$ regressing the probability of trading for each bond on each venue:

$$
\operatorname{Prob}\left(\operatorname{trade}_{i, t, j}\right)=\operatorname{Prob}\left(\alpha_{i}+\beta X_{i t}+\varepsilon_{i t}>0\right)
$$

where trade $_{i, j, t}$ is a dummy variable equal to one if bond $i$ is traded on venue $j$ in day $t$ and zero otherwise. Although this work considers three trading venues overall (DomesticMOT, EuroTLX and ExtraMOT), four regressions are run since bonds listed DomesticMOT and ExtraMOT are also traded on EuroTLX. Independent variables are stacked in matrix $X_{i t} ; \alpha$ and $\beta$ represent the parameters to be estimated. Finally, the cumulative distribution function of the error $\varepsilon$ is logistic: $F(\varepsilon)=\left[1+e^{-\varepsilon}\right]^{-1}$.

37 The coupon structure matters as long as callability modifies duration. The call option acts as an implied insurance by protecting the issuer from adverse interest rates changes ad is found to reduce trading volume.

38 Some authors refer to it also as commonality, or synchronicity, in liquidity (Kamara, Lou, and Sadka 2008; Acharya and Pedersen, 2005; Brockman and Chung, 2008; Karolyi, Lee, and Van Dijk 2012).

39 The panel probit model is ruled out since it does not guarantee convergence of the estimation algorithm; in particular, such an outcome occurs with the ExtraMOT sample. Fixed effect panel logit is ruled out since it rises incidental parameter issues. 
The regressors $\left(X_{i t}\right)$ can be grouped into the following categories: bond features, issuer attributes, and market conditions. Bond features are $i$ ) issue size, $i i$ ) complexity (either as plain-vanilla or structured), iii) time-to-maturity (either in years or as a ratio to the total life of the product), and the iv) minimum trading size (a proxy to distinguish between retail and non-retail securities). ${ }^{40}$ As for time-to-maturity, both a linear and a quadratic term has been tested. ${ }^{41}$ In our sample, size and complexity are highly correlated, so that they are not included in the same regression model.

Nationality and industry represent the issuers' attributes. Since such variables exhibit a strong crosscorrelation with the issue size, they enter the model specification separately from the issue size. Our model specification includes the issuer's credit risk proxied by three indicators: the issuer rating released by Moody's ${ }^{42}$, the probability of default (expected default frequency or EDF ${ }^{43}$ ) and the issuer's credit default swap (CDS) quotation. The official rating is updated whenever a change occurs. CDS quotations add a measure of credit risk since they capture the linkage between bond and CDS markets. The expected sign of the credit risk effect is ambiguous. Generally speaking, if the volume (and the probability of trade occurrence) increases as the bond ex ante risk rises then the impact should be positive. Ambiguity is higher for CDS: if an issuer is actively used as underlying for CDS, bond liquidity of the same issuer may increase especially during financial crises and for investment grade securities, preventing investors from fire sales (Massa and Zhang, 2012).

As for market conditions, we included the stock market volatility, the information risk (proxied by bond daily closing price variability), the Italian sovereign CDS quotations, and a financial crisis indicator. Sovereign CDS quotation, stock market volatility and the issuer's CDS quotations enter alternative model specifications to avoid multicollinearity, given that they are highly correlated.

The crisis indicator is defined using a data driven approach. The beginning and the end of the financial crisis are identified through a market dependent periodization, i.e. looking at the pattern of a financial stress index (Galliani et al., 2013). Our stress index is the quality spread, i.e. the riskpremium computed as the difference between the yields of AAA and BBB European non-financial bonds. We thus define a "crisis" dummy variable which is equal to one when the index exceeds the third quartile of its sample distribution. ${ }^{44}$ The crisis spans from July 2011 to July 2012 . We also consider the interaction between the dummy and a set of explicative variables in order to test whether their impact on liquidity changes during financial turmoil $\left(\alpha \cdot d u m m y_{\text {crisis }} \cdot X_{i t}+\beta X_{i t}\right)$.

\subsection{The estimation results}

\section{Evidence from DomesticMOT and EuroTLX}

The probability of trading occurrence across the two trading venues (DomesticMOT and EuroTLX) is affected by a set of variables (Table 3; see also Appendix 3 for alternative model specifications).

Bank bonds are estimated to trade less frequently than non-financial bonds. Bonds issued by Italian companies are traded more frequently than foreign ones. As expected, bonds with long residual

40 As mentioned above, this variable shows enough variability only for bonds traded on EuroTLX and ExtraMOT. 41 As an alternative to time to maturity, we used also the bond age (i.e. time since launch).

42 We map the Moody's rating scale with an increasing integer number, as it is frequently reported in the literature. We used the issuer ratings provided that all the securities in our data set are represented by senior unsecured bonds. In one case, the Moody's rating was not available and we used the S\&P rating.

43 As measured by Moody's KMV. Default is defined as failure to make scheduled principal or interest payments. According to the Moody's EDF model, a firm defaults when the market value of its assets (the value of the ongoing business) falls below its liabilities payable (the default point). EDF exhibits higher variability than the official rating because it considers the issuers' specific features such as capital structure, market value, and the volatility of its assets.

44 Source: JP Morgan Maggie European credit risk index, daily data. 
maturity are traded frequently (negative age coefficient); while, bond price variability (information risk) lowers the probability of trade occurrence on both DomesticMOT and EuroTLX.

With regard to the statistically significant factors having a different impact on liquidity depending on the trading venue. Complex bonds are traded less frequently on DomesticMOT, while the opposite holds on EuroTLX. The increase of the issuer's credit default swap prices (Issuer Cds quotations) enhances liquidity only on DomesticMOT. Moreover, trade occurrence appears to be negatively influenced by rating announcements only on DomesticMOT. Among the variables capturing the correlation between equity and bond markets, the evidence is mixed depending on the trading venue since stock market volatility has a negative impact on liquidity on DomesticMOT only. Changes in the sovereign CDS quotations reduces liquidity on EuroTLX.

Table 3 - Determinants of trade occurrence on DomesticMOT and EuroTLX

\begin{tabular}{|c|c|c|}
\hline Explanatory variables & Domestic MOT & EuroTlx \\
\hline Bank bonds & \multicolumn{2}{|c|}{ Bank bonds estimated to trade less frequently than non-financial b.; greater impact on EuroTLX } \\
\hline Nationality of bonds & \multicolumn{2}{|c|}{ Italian bonds estimated to trade more frequently than foreign bonds } \\
\hline Complexity (structured bonds) & $\begin{array}{l}\text { Structured bonds traded less frequently than } \\
\text { plain vanilla ones }\end{array}$ & $\begin{array}{l}\text { Structured bonds traded more frequently } \\
\text { than plain vanilla ones }\end{array}$ \\
\hline Time to maturity/age & \multicolumn{2}{|c|}{ Seasoned bonds estimated to trade less frequently } \\
\hline Issuer Cds quotations & Positive, but almost negligible impact & Statistically insignificant \\
\hline Issuer rating & $\begin{array}{l}\text { Lower probability of trade for worse rated and } \\
\text { downgraded bonds }\end{array}$ & Statistically insignificant \\
\hline Issuer EDF & \multicolumn{2}{|c|}{ Statistically insignificant } \\
\hline Information risk & Negative impact on bonds trade & Negative impact (greater magnitude) \\
\hline Stock market volatility & Negative impact on bonds trade & Statistically insignificant \\
\hline
\end{tabular}

Table 4 compares the impact of the financial market crises on the probability of trading on DomesticMOT and EuroTLX (Appendix 3 for further details). As expected the dummy crisis has a negative sign because the probability of trading has diminished on both venues during the financial turmoil. In particular, the dummy crisis amplifies the impact of some explanatory variables, not always in both venues though. Italian bank bonds suffer from the deterioration of market conditions on EuroTLX only. Conversely, rating changes are estimated to have a higher impact during crisis times on DomesticMOT only. 
Table 4 - Impact of sovereign debt crisis on trade occurrence on DomesticMOT and EuroTLX

\begin{tabular}{|c|c|c|}
\hline $\begin{array}{l}\text { Explanatory variables interacted } \\
\text { with the dummy Crisis }\end{array}$ & DomesticMOT & EuroTlx \\
\hline Bank sector & No significant change during crisis time & $\begin{array}{l}\text { Trade occurrence of bank bonds tends to } \\
\text { lower during crisis }\end{array}$ \\
\hline Nationality & No significant change during crisis time & $\begin{array}{l}\text { Trade occurrence of Italian bonds tends to } \\
\text { lower during crisis (even more when Italian } \\
\text { sovereign Cds quotations rise) }\end{array}$ \\
\hline Complexity & \multicolumn{2}{|c|}{ Statistically insignificant } \\
\hline Age & \multicolumn{2}{|c|}{ Trade occurrence of seasoned products tends to rise } \\
\hline Issuer Cds quotations & $\begin{array}{l}\text { During crisis periods an increase of Cds quotations } \\
\text { lowers the probability of trading }\end{array}$ & No significant change during crisis time \\
\hline Issuer rating & $\begin{array}{l}\text { Downgrade/upgrade tends to lower/enhance } \\
\text { trade occurrence during crisis }\end{array}$ & No significant change during crisis time \\
\hline Issuer expected default frequency & \multicolumn{2}{|c|}{ No significant changes during crisis time } \\
\hline Information risk & \multicolumn{2}{|c|}{ No significant change during crisis time (larger impact) } \\
\hline Italian stock market volatility & \multicolumn{2}{|c|}{ No significant changes during crisis time } \\
\hline
\end{tabular}

\section{Evidence from ExtraMOT and EuroTLX}

The econometric analysis performed on the subsample of bonds fragmented across ExtraMOT and EuroTLX suggests that the explanatory variables broadly exhibit the same impact on trade occurrence, with the exceptions of residual maturity, issuer industry and credit risk. In particular, on ExtraMOT the probability of trading seasoned bonds increases; while, the opposite holds on EuroTLX; the issuer industry is relevant on EuroTLX only (bank bonds traded less frequently than non-financial bonds). Rating announcements affect trade occurrence on EuroTLX (Table 5, Appendix 3 for more details).

Table 5 - Determinants of trade occurrence on ExtraMOT and EuroTLX

\begin{tabular}{|c|c|c|}
\hline Explanatory variables & ExtraMQT & EuroTlx \\
\hline Age & $\begin{array}{l}\text { Seasoned productsare more frequently } \\
\text { traded }\end{array}$ & Aged bonds less frequently traded \\
\hline Bank bonds & Statistically insignificant & $\begin{array}{l}\text { Bank bonds traded less frequently than } \\
\text { non-financial bonds }\end{array}$ \\
\hline Issuer nationality & \multicolumn{2}{|c|}{ Italian bonds traded more frequently than foreign ones } \\
\hline Structured bonds & \multicolumn{2}{|c|}{ Statistically insignificant } \\
\hline Lot size & \multicolumn{2}{|c|}{ Retail products more frequently traded } \\
\hline Issue size & \multicolumn{2}{|c|}{ Bonds with higher amount outstanding more frequently traded } \\
\hline Issuer Cds quotations & \multicolumn{2}{|c|}{ Positive impact } \\
\hline Sovereign Cds quotations & \multicolumn{2}{|c|}{ Positive (marginal) impact } \\
\hline Issuer rating & $\begin{array}{l}\text { Downgrade marginally reduces trade } \\
\text { occurrence }\end{array}$ & Downgrade increases trade occurrence \\
\hline Issuer Expected Default Frequency & \multicolumn{2}{|c|}{ Trade occurrence more likely when EDF increase } \\
\hline Information risk & \multicolumn{2}{|c|}{ Positive impact on trade occurrence } \\
\hline Stock market volatility & \multicolumn{2}{|c|}{ Negative effect on trade frequency } \\
\hline
\end{tabular}


The interaction between the dummy crisis and bonds' attributes highlights that only few attributes have an impact on the probability of trade occurrence (variable across venues). In particular, in bad market conditions the probability of trading bank bonds decreases on EuroTLX. Similarly, market turbulence significantly reduces the probability of retail bonds trading on EuroTLX. But, on ExtraMOT both Italian bonds and complex bonds experience a more frequent trading (Table 6).

Table 6 - Impact of sovereign debt crisis on trade occurrence on ExtraMOT and EuroTLX

\begin{tabular}{|c|c|c|}
\hline $\begin{array}{l}\text { Explanatory variables interacted with } \\
\text { the dummy Crisis }\end{array}$ & ExtraMoT & EuroTlx \\
\hline Bank sector & No significant change during crisis time & $\begin{array}{l}\text { Trade of bank bonds tends to lower } \\
\text { during financial market turbulence }\end{array}$ \\
\hline Nationality & $\begin{array}{l}\text { Trade occurrence of Italian bonds tend to } \\
\text { rise during financial market turbulence }\end{array}$ & No significant change during crisis time \\
\hline Complexity & Trade significantly increases during crisis & No significant change during crisis time \\
\hline Lot size & $\begin{array}{l}\text { Trade occurrence of retail products tends } \\
\text { to increase during crisis }\end{array}$ & $\begin{array}{l}\text { Trade occurrence of retail products tends } \\
\text { to lower during crisis }\end{array}$ \\
\hline $\begin{array}{l}\text { Issue size } \\
\text { Age } \\
\text { Issuer Cds quotations } \\
\text { Issuer rating } \\
\text { Issuer EDF } \\
\text { Information risk } \\
\text { Italian stock market volatility }\end{array}$ & \multicolumn{2}{|c|}{$\begin{array}{l}\text { Greater impact of the explanatory variables on trade occurrence during the sovereign } \\
\text { debt crisis }\end{array}$} \\
\hline
\end{tabular}

\subsection{The marginal effects}

The magnitude of explanatory variables' impact on trade occurrence is quantified by estimating the average marginal effects of each significant variable on the probability of trade across DomesticMOT, EuroTLX and ExtraMOT. The analysis is also interesting since it allows us to gauge the extent to which the crisis magnified the effect of the significant variables (Appendix 3).

Some bonds' attributes, such as complexity and MTS, and some issuer's attributes, such as industry and nationality, exert a relevant effect on the probability of trading.

Indeed, for bonds traded across DomesticMOT and EuroTLX the probability of trading for bank bonds decreases on average by -0.5 on EuroTLX. Regarding issuer's nationality, the most relevant impact on the probability of trade occurrence is found for Italian bonds traded on EuroTLX $(+0.4$ for bonds traded jointly on DomesticMOT and +0.5 for bonds traded jointly on ExtraMOT). As observed above, structured bonds tend to be more frequently traded on EuroTLX, while the reverse is true on DomesticMOT. Indeed, the probability of trade occurrence for structured bonds increases by 0.4 on EuroTLX, while it decreases by 0.2 on DomesticMOT. If MTS is 1,000 euro (retail), the probability of trade occurrence increases by 0.1 on ExtraMOT and by 0.5 on EuroTLX. ${ }^{45}$

Lastly, we measured the impact of the sovereign debt crisis (Appendix 3). Results are in line with the empirical evidence reported so far. As for bonds traded on DomesticMOT and EuroTLX, the crisis affects the explanatory variables in a different way across the two venues. On DomesticMOT,

45 Less relevant, instead, are the quantitative impacts of issuer Cds quotations, information risk and Italian stock market volatility. 
during the sovereign debt crisis the impact of the issuer CDS quotations reversed (i.e. became negative); whereas the negative marginal effects of rating and information risk widened. On EuroTLX, instead, the outburst of the debt crisis lowers the probability of trading of Italian bank bonds (while trading of non-financial bonds remains unaffected); whereas, time to maturity loses statistical relevance with respect to tranquil periods, it keeps showing a negative sign though.

As for bonds dual-listed on ExtraMOT and EuroTLX, the sovereign debt crisis tends to raise the probability of trade occurrence of Italian retail structured bonds traded on ExtraMOT; whilst on EuroTLX financial market turbulence affects mainly the probability of trading of seasoned bonds (bonds with a lower time to maturity trade more during bad times).

\section{The impact of fragmentation on liquidity: evidence from a matched sample of bank bonds}

This Section compares the liquidity level of bank bonds fragmented across DomesticMOT and EuroTLX with otherwise similar bank bonds traded only on DomesticMOT. In order to carry out such a comparison, we resorted to the matched sample approach, given that no counterfactual evidence is available for fragmented bonds, i.e. it is not possible to observe their liquidity level if they were not traded on multiple venues. Matched sample techniques are frequently employed in the finance literature, especially in market microstructure studies. Such methods, in fact, allow comparing the execution costs on different exchanges, or across various groups of securities. For instance, Davies and Kim (2009) consider two groups of stocks that differ in their listing status and match them in pairs according to various characteristics. We focus on bank bonds because the sample size of non-financial bonds traded on DomesticMOT only is not suitable for the matching exercise. Indeed, during the sample period, there are 705 non-fragmented bank bonds (792 securities minus 87 fragmented bonds); whereas, the number of non-financial bonds traded on DomesticMOT only is 5 (out of 18; see Table 1). Similarly, we rule out bonds jointly traded on ExtraMOT and EuroTLX because the majority of the securities traded on ExtraMOT are dual-listed (more precisely, 104 out of 109 bank bonds, and 205 out of 216 non-financial bonds; see Table 1 ). Finally, we do not focus on EuroTLX alone because we aim at comparing the liquidity conditions of dual-listed and non-fragmented bonds on a regulated market (i.e. DomesticMOT) rather than on an Mtf (i.e. EuroTLX), given the relevance of this topic on policy grounds.

Therefore, we apply the matching sample approach to 705 bank bonds traded on DomesticMOT only from January 2010 until June 2013 in order to draw a matched sample with 87 securities jointly traded on DomesticMOT and EuroTLX. The non-fragmented securities account for about $90 \%$ of all outstanding bank bonds traded on DomesticMOT both in terms of total number of securities and of average market value, while fragmented bonds correspond to $10 \%$ of the total number of securities and to $54 \%$ of the average total market value. ${ }^{46}$

Matching relies on a nearest-neighbor approach, minimizing the difference (matching error) between the two groups of bank bonds with respect to a set of criteria. Such criteria refer to both securities' and issuers' attributes. As for securities attributes, we considered the market value ${ }^{47}$, the complexity (plain vanilla versus structured bond), time-to-maturity and MTS. As for the issuers' attributes, we take into account nationality (Italian versus foreigner) and rating. The matching

46 The average market value is computed over January 2010-June 2013 considering market price and issue size.

47 Matching is based on the average bond market value (the product between the amount issued and the market price) over the span January 2010-June 2013. Market value is preferred to the issue size as a matching criterion in order to select bonds that might be deemed similar also with respect to the market price trend. The choice of the market value is also in line with Davies and Kim (2008), who matched stocks by their market capitalization and their market price. 
sample is thus constructed by minimizing the matching errors (i.e. the absolute distance) between matching pairs with respect to the characteristics mentioned above. ${ }^{48}$ The matched pairs are reported in Appendix 4.

In order to assess the impact of fragmentation on liquidity levels, we compare the averages over the sample period of the four liquidity indicators for the dual-listed bonds with those computed for the non-fragmented securities. As a robustness check, we perform both the $t$-test and the Wilcoxon test (see Appendix 4, Table a4.2 for details). Moreover, given the evidence reported in Section 4 showing that Italian bonds traded on DomesticMOT are more liquid than foreign ones along all the liquidity dimensions but the turnover ratio, we also report evidence for the subsample of Italian bank bonds (40 securities), in order to check whether they behave differently.

The analysis shows that liquidity of non-fragmented securities is higher than that of dual-listed bonds for three out of four indicators (i.e. zero-trade, turnover ratio and price impact); whereas, the differences in the Roll indicator are not statistically significant. However, this evidence does not hold for the subsample of the Italian banks bonds: the liquidity of dual-listed securities (zero-trade, price impact, and Roll) is higher than that of non-fragmented bonds (the difference is not statistically significant for the turnover ratio). ${ }^{49}$ The discrepancies between the whole sample and the Italian sub-sample is due to the foreign securities, which on average are characterized by a lower market value and issue size $\mathrm{e}^{50}$ and are less liquid if fragmented.

As a robustness check, we estimate a multivariate model regressing the differences in the liquidity levels (computed for the dual-listed and the non-fragmented bonds) on the differences in the factors exploited to draw the matching sample (market value, time-to-maturity, and rating). ${ }^{51}$ Such check is equivalent to test whether the assumption of perfectly homogenous securities holds or, in other words, whether discrepancies in the liquidity conditions across the two sample of securities are related to differences in their attributes or to the features of the trading venues. Results show that any of the variables used to draw the matching sample is jointly significant (at $5 \%$ confidence level), neither for the whole sample nor for the Italian bank bonds sub-sample. Empirical evidence thus seems to support the hypothesis of homogeneity of non-fragmented matched securities and dual-listed bonds.

\section{Concluding remarks}

This paper investigates the liquidity conditions and the determinants of trading for a sample of nongovernment bonds fragmented across the main Italian retail bond markets (DomesticMOT, ExtraMOT, and EuroTLX) from January 2010 to June 2013. In order to account for different

48 Only two out of the six characteristics used to match pairs are computed as averages (i.e. market value and rating score). Therefore we could not apply a statistical test to evaluate the significance of the absolute distance between each pair of bonds. Then, we decided to use several attributes besides market value and rating, after checking that if we had relied only on market value and rating scores, it would have led to a very different selection of pairs of bonds in terms of maturity, with a significant impact on the liquidity analysis.

49 This result is confirmed both by the $t$-test and the Wilcoxon test.

50 During the sample period, Italian bank bonds have an average market value of 262 million euros (versus 266 of the non-fragmented); while, figures of foreign securities amount to 144 and 146 million euros respectively. Similarly, the fragmented Italian bank bond have an average issue size of 260 million euros (versus 247 for the non-fragmented); while, the corresponding figures for foreign securities amount to 141 and 95 million euros, respectively.

51 In multivariate regressions several dependent variables are jointly regressed on the same independent variables. Individual coefficients and standard errors are identical to those obtained by estimating each equation separately, but the coefficients' significance can be jointly tested across equations because between-equation covariances are estimated. The multivariate regression is also supported by the Breusch-Pagan test, since the residuals of the explanatory variables turn out to be not independent of each other. 
dimensions of liquidity, four measures are considered: zero-trade, turnover ratio, Amihud statistics and Roll indicator. Evidence from the principal component analysis supports the use of all these indicators since they equally contributed to the liquidity conditions of dual-listed bonds over the entire sample period. Indicators are computed separately for bank bonds and non-financial bonds in order to address eventual differences in trading activity due the issuer's industry. Also the impact of the sovereign debt crisis on liquidity levels has been assessed. Focusing on liquidity of fragmented bonds traded across different venues allows us to test whether, in spite of fragmentation, Italian corporate bond markets may be regarded as integrated and competitive; hence, our approach is helpful to examine the effects following the abolition of the so-called concentration rule pursued by the MiFID. This is a very relevant topic on policy grounds and it has been tackled by the Italian legislator extending pre- and post-trade transparency rules to non-equity markets, in spite of the fact that the Directive envisaged such requirement for equity markets only.

Overall, the evidence is not clear-cut since the empirical findings depend upon a variety of factors: the liquidity indicator, the issuer's sector, and on the trading venue. Although the Amihud priceimpact statistics and the Rolls spread suggest EuroTLX being more liquid, liquidity levels appear similar across DomesticMOT and EuroTLX. But, EuroTLX turns out to be more liquid than ExtraMOT. Moreover, bank bonds fragmented across DomesticMOT and EuroTLX tend to be less liquid than non-financial securities and seem to have suffered more, in terms of lower liquidity, during the sovereign debt crisis. Whereas, bank bonds fragmented across ExtraMOT and EuroTLX are more liquid than bonds issued by non-financial companies.

Both the univariate and the multivariate analysis highlighted that bonds' characteristics and market turbulences may impact differently on liquidity depending on the trading venue, thus pointing to the role of microstructural features, such as the presence of liquidity providers and the information released on the liquidity conditions of the financial instruments.

Finally, the paper sheds light on the effect of fragmentation by comparing liquidity levels of bank bonds fragmented across DomesticMOT and EuroTLX with otherwise similar bank bonds traded only on DomesticMOT. The impact of fragmentation seems to depend on bond attributes, being the issue size a key driver of liquidity. Actually, depending on the liquidity indicator, Italian bank bonds -whose issued amount is higher than that of foreign bonds- do not seem to be negatively affected by fragmentation, whereas foreigner bonds are less liquid if dual-listed.

This study adds to the existing literature by providing new empirical evidence on the liquidity of Italian non-government bonds. To our knowledge, this is the first work to explore the impact of fragmentation on the liquidity of non-government bonds. Our findings are consistent with the idea that transparency rules and market rules promoting liquidity provisions may contribute to the development of an integrated secondary bond market. To this respect, this work is also relevant on policy grounds, especially within the current European regulatory framework, which has recently undergone a change towards a greater transparency in non-equity markets. 


\section{References}

Acharya, V.V. and Pedersen L.H. (2005), Asset pricing with liquidity risk. Journal of Financial Economics, 77 , 375-410.

Alexander, G., Edwards A., and Ferri M. (2000), The determinants of the trading volume of high yield corporate bonds. Journal of Financial Markets, 3, 177-204.

Amihud, Y. (2002), Illiquidity and stock returns: cross-section and time series effects. Journal of Financial Markets, 5, 31-56.

Annaert, J. and De Cesteur, M.J.K. (1999), Modelling European credit spreads. Available at http://citeseerx.ist.psu.edu/viewdoc/download?doi=10.1.1.4.9609\&rep $=$ repl\&type $=p d f$.

Bao, J., Pan. J., and Wang J. (2009), Liquidity of corporate bonds. Available at http://www.haas.berkeley.edu/groups/finance/bond_liquidity.pdf.

Beber A. and Pagano, M. (2008), Measuring liquidity in the TLX market. mimeo.

Bollen, N. and Whaley R.E. (1998), Are teenies better? Journal of Portfolio Management, 25, 10-24.

Brockman, P. and Chung D.Y. (2008), Commonality under market stress: evidence from an order-driven market. International Review of Economics \& Finance, 17, 179-196.

CFA (2011), An examination of transparency in European bond markets. Available at http://www.cfapubs.org/doi/pdf/10.2469/ccb.v2011.n5.1.

Consob (2013), Annual Report. www.consob.it

Davies, R.J. and Kim, S.S. (2009), Using matched samples to test for differences in trade execution costs. Journal of Financial Markets, 12(2), 173-202.

De Jong, F. and Driessen, J. (2006), Liquidity risk premia in corporate bond markets. Available at ssrn.com

Diaz, A. and Navarro, E. (2002), Yield spread and term to maturity: default vs liquidity. European Financial Management, 8, 449-477.

Elton, E. J. and Green, T.C. (1998), Tax and liquidity effects in pricing governments bonds. Journal of Finance, $53,1533-1562$.

Ericsson, J. and Renault, O. (2001), Liquidity and credit risk. ssrn.com.

Fenn, G. (2000), Speed of issuance and the adequacy of disclosure in the 144A high-yield debt market. Journal of Financial Markets, 56, 383-405.

Fleming, M.J. (2003), Measuring treasury market liquidity. Economic Policy Review, pp. 83-108.

Fong, K., Holden, C.W., and Trzcinka, C.A. (2011), What are the best liquidity proxies for global research? mimeo.

Galliani, C., Petrella G., and Resti, A. (2013), The liquidity of European corporate and government bonds: drivers and sensitivity to different market conditions. mimeo.

Goyenko, R.Y., Holden, C.W., and Trzcinka, C.A. (2009), Do liquidity measures measure liquidity?. Journal of Financial Economics, 92, 153-181.

Grasso, R., Linciano, N., Pierantoni, L., and Siciliano, G. (2010), Bond issued by Italian banks: risk and return characteristics. Available at SSRN: http://ssrn.com/abstract $=1919524$ or http://dx.doi.org/10.2139/ssrn.1919524, Quaderno di Finanza Consob n. 67, luglio 2010.

Hasbrouck, J. (2004), Liquidity in the futures pits: inferring market dynamics from incomplete data. Journal of Financial and Quantitative Analysis, 39, 305-326.

Hasbrouck, J. (2009), Trading costs and returns for US equities: estimating effective costs from daily data. Journal of Finance, 64, 1445-1447.

Hong, G. and Warga, A.D. (2000), An empirical study of corporate bond market transactions. Financial Analyst Journal, 56, 32-46. 
Hotchkiss, E. S. and Ronen, T. (2002), The informational efficiency of corporate bond market: an intraday analysis. Review of Financial Studies, 15, 1325-1354.

Hotchkiss, E. S. and Jostova, G. (2007), Determinants of corporate bond trading: a comprehensive analysis. Available at SSRN: http://ssrn.com/abstract=1001459 or http://dx.doi.org/10.2139/ssrn.1001459.

Houweling, P., Mentink, A., and Vorst, T. (2005), Comparing possible proxies of corporate bond liquidity. Journal of Banking and Finance, 29, 1331-1358.

Huang, R. D. and Stoll, H.R. (1996), Dealer versus auction markets: a paired comparison of execution costs on NASDAQ and the NYSE. Journal of Financial Economics, 41, 313-357.

IOSCO (2004), Transparency of corporate bond markets. Available at http://www.iosco.org/pubdocs/pdf/IOSCOPD168.pdf.

IOSCO (2005), Strengthening capital markets against financial fraud. Available at http://www.iosco.org/pubdocs/pdf/IOSCOPD192.pdf.

Kamara, A., Lou, X. and Sadka, R. (2008), The divergence of liquidity commonality in the cross-section of stocks. Journal of Financial Economics, 89, 444-466.

Karolyi, G., Lee, K.H. and Van Dijk, M. (2012), Understanding commonality in liquidity around the world. Journal of Financial Economics, 105, 82-112, doi:10.1016/j.jfineco.2011.12.008.

Lesmond, D., Ogden, J., and Trzcinka, C. (1999), A new estimate of transaction costs. Review of Financial Studies, 12, 1113-1141.

Lesmond, D. (2005), Liquidity of emerging markets. Journal of Financial Economics, 77, 411-452.

Massa, M. and Zhang, L. (2012), CDS and the liquidity provision in the bond market. INSEAD 2012/114/FIN.

McGinty, L. (2001), Issue size versus liquidity in credit. J.P. Morgan Fixed Income Research.

Nielsen, J.D., Feldhutter P., and Lando D. (2012), Corporate bond liquidity before and after the onset of the subprime crisis. Journal of Financial Economics. 103, 471-492.

O'Hara, M. (1995), Market microstructure theory. Blackwell Publishers, Cambridge MA.

Pastor, L. and Stambaugh, R. (2003), Liquidity risk and expected stock returns. Journal of Political Economy, $111,642-685$.

Petrella, G. and Resti, A. (2013), What drives the liquidity of Eurozone sovereign bonds? Assessing the appropriateness of new rules on bank liquidity assets. mimeo.

Petrella, G. and Resti, A. (2013), Basilea 3 e la liquidità delle obbligazioni governative e private in Europa. Bancaria, 3, 22-36.

Roll, R. (1984), A simple implicit measure of the effective bid-ask spread in an efficient market. Journal of Finance, 39, 1127-1139.

Sarig, O. and Warga, A.D. (1989), Bond price data and bond market liquidity. Journal of Financial and Quantitative Analysis, 24, 367-378.

Sarr, A. and Lybek T. (2002), Measuring liquidity in financial markets. IMF Working Paper No. 02/232.

Warga, A.D. (1992), Bond returns, liquidity and missing data. Journal of Financial and Quantitative Analysis, $27,605-617$. 


\section{Appendix 1}

\section{Sample selection: some methodological issues}

One of the key issues about the analysis regards the classification of bonds in terms of the issuer's industry, the country of issue, the coupon structure, etc...

As for the issuer's industry classification, we faced two options: either an institutional (and formal) approach or a substantial one. We opted for an intermediate solution which is also followed by Borsa Italiana, since $i$ ) it offers a simple and practical distinction between the financial and the non-financial sector (including almost only bank issuers in the former group and aggregates all other industries, with the residual exception of insurance, in the latter); $i i$ ) although simplified, such an approach is satisfactory, effective, and realistic for our purposes as long as it is used by intermediaries when offering bonds to retail investors (whose concern is particularly relevant to us); furthermore, iii) on the one hand, official classifications (such as the UIC one) are too rigorous and formal, resulting in an unnecessary generic attribution to macro-sectors (e.g. financial or nonfinancial companies); $i v$ ) on the other hand, classifications suggested by info providers (such as Reuters or Bloomberg) might be too industry-specific ${ }^{1}$, and go beyond the scope of this study. The choice between a formal versus a substantial approach affects both descriptive statistics and subsequent analysis, also because it has to be considered the common practice followed by large companies to optimize their financial operations performing the issuance activity through a dedicated financial vehicle company (e.g.: Telecom XY Finance on behalf of Telecom XY) ${ }^{2}$.

However, while reviewing Borsa Italiana's industry attribution for each bond both in the market and in the sample list, we have corrected some patently wrong attributions (typically, a bank issuer classified as 'corporate', meaning 'non-financial', or vice-versa). Such corrections may have in turn accounted for further discrepancies with aggregate official market data on turnover, and obviously influenced our subsequent analysis and conclusions, which deeply rely upon the key distinction between banking and corporate issuers.

A further source of uncertainty is related to the information concerning the issuer's nationality and the country of issue. Again, we prefer substance over form, using the (ultimate) parent company's country (of incorporation) rather than the vehicle's country. In some cases we have adopted Reuters's classification, finding it more detailed and complete than that provided by Borsa Italiana.

As far as bonds coupon structure is concerned, there are lots of options available from Reuters or Bloomberg (we ruled out the Borsa Italiana's data for sake of parsimony). However, we followed the approach previously adopted by Grasso, Linciano, Pierantoni, and Siciliano (2010), i.e. we basically distinguish between 'simple' and 'structured' bonds. The 'simple' class is composed by fixed and floating rate coupon bonds (this class includes also zero coupon bonds); while, the 'structured' group is more heterogeneous since it includes index linked, equity linked, step up, step down bonds, and, more generally, bonds with a derivative component.

1 In some cases they also might disagree on the ultimate financial or non-financial nature of the issuer.

2 For instance, a formal classification would consider these financial companies as part of the financial sector, along with banks and other monetary or credit institutions, whereas we believe that they represent a part of the telecom sector issuance activity and should be classified accordingly.

$3 \mathrm{We}$ find few ambiguous cases (of little significance in terms of turnover). 


\section{Appendix 2}

Table a2.1 - Liquidity of bonds fragmented across ExtraMOT and EuroTLX by lot size (percentage values)

\begin{tabular}{|c|c|c|c|c|c|}
\hline & Indicator & MTS $<=1000^{1}$ & MTS $>1000^{1}$ & $\begin{array}{l}\text { Test } \\
\text { significance }\end{array}$ & Results \\
\hline \multicolumn{6}{|l|}{ ExtraMOT } \\
\hline \multirow[t]{4}{*}{ bank } & Amihud & 47.3 & 16.3 & $\left({ }^{*}\right)$ & Greater lot size more liquid \\
\hline & Roll & 62.2 & 57.1 & & Same liquidity levels \\
\hline & Turnover & 0.0 & 0.2 & $\left({ }^{\star}\right)$ & Greater lot size more liquid \\
\hline & Zero-trade & 72.0 & 71.7 & & Same liquidity levels \\
\hline \multirow[t]{4}{*}{ non-financial } & Amihud & 51.2 & 5.7 & $\left({ }^{*}\right)$ & Greater lot size more liquid \\
\hline & Roll & 64.4 & 56.8 & & Same liquidity levels \\
\hline & Turnover & 0.1 & 0.2 & $\left({ }^{*}\right)$ & Greater lot size more liquid \\
\hline & Zero-trade & 73.4 & 76.5 & $\left({ }^{*}\right)$ & Smaller lot size more liquid \\
\hline \multicolumn{6}{|l|}{ EuroTLX } \\
\hline \multirow[t]{4}{*}{ bank } & Amihud & 17.4 & 5.5 & $\left({ }^{\star}\right)$ & Greater lot size more liquid \\
\hline & Roll & 38.8 & 42.4 & & Same liquidity level \\
\hline & Turnover & 0.3 & 0.8 & $\left({ }^{*}\right)$ & Greater lot size more liquid \\
\hline & Zero-trade & 40.2 & 45.9 & $\left({ }^{\star}\right)$ & Smaller lot size more liquid \\
\hline \multirow[t]{4}{*}{ non-financial } & Amihud & 16.4 & 1.2 & $\left({ }^{*}\right)$ & Greater lot size more liquid \\
\hline & Roll & 35.3 & 53.1 & $\left({ }^{\star}\right)$ & Smaller lot size more liquid \\
\hline & Turnover & 0.2 & 0.4 & $\left({ }^{*}\right)$ & Greater lot size more liquid \\
\hline & Zero-trade & 45.7 & 45.3 & & Same liquidity levels \\
\hline
\end{tabular}

Source: our elaborations on Consob database. ${ }^{1}$ MTS $=$ Minimun trading size. Sample average of the liquidity indicators computed on monthly data in percentage values. $(*)=$ Null hypothesis rejected at $95 \%$ confidence level. Higher values for Amihud, Roll, zero-trade indicators mean lower liquidity levels. All bonds fragmented across DomesticMOT and EuroTLX have a lot size lower than or equal to 1,000 euros and therefore are not eligible for the analysis herein reported. 
Table a2.2 - Dual-listed bond liquidity by issuer's nationality (percentage values)

\begin{tabular}{|c|c|c|c|c|c|}
\hline & Indicator & Italian ${ }^{1}$ & Foreign ${ }^{1}$ & $\begin{array}{l}\text { Test } \\
\text { significance }\end{array}$ & Inference \\
\hline \multicolumn{6}{|l|}{ DomesticMOT } \\
\hline \multirow[t]{4}{*}{ bank } & Amihud & 9.1 & 63.0 & $\left({ }^{*}\right)$ & Italian bonds more liquid \\
\hline & Roll & 37.3 & 67.0 & $\left({ }^{*}\right)$ & Italian bonds more liquid \\
\hline & Turnover & 1.8 & 2.0 & & Same liquidity levels \\
\hline & Zero-trade & 24.4 & 42.1 & $\left({ }^{*}\right)$ & Italian bonds more liquid \\
\hline \multicolumn{6}{|c|}{ EuroTLX (bonds also traded on DomesticMOT) } \\
\hline \multirow[t]{4}{*}{ bank } & Amihud & 20.2 & 22.7 & & Same liquidity levels \\
\hline & Roll & 51.9 & 45.4 & & Same liquidity levels \\
\hline & Turnover & 1.0 & 2.1 & $\left({ }^{\star}\right)$ & Foreign bonds more liquid \\
\hline & Zero-trade & 36.7 & 39.4 & & Same liquidity levels \\
\hline \multicolumn{6}{|l|}{ ExtraMOT } \\
\hline \multirow[t]{4}{*}{ bank } & Amihud & 9.8 & 29.7 & $\left({ }^{\star}\right)$ & Italian bonds more liquid \\
\hline & Roll & 57.8 & 64.2 & & Same liquidity levels \\
\hline & Turnover & 0.3 & 0.0 & $(*)$ & Italian bonds more liquid \\
\hline & Zero-trade & 60.3 & 82.5 & $\left({ }^{*}\right)$ & Italian bonds more liquid \\
\hline \multirow[t]{4}{*}{ non-financial } & Amihud & 14.2 & 55.3 & $\left({ }^{*}\right)$ & Italian bonds more liquid \\
\hline & Roll & 59.1 & 67.6 & & Same liquidity levels \\
\hline & Turnover & 0.3 & 0.0 & $\left({ }^{*}\right)$ & Italian bonds more liquid \\
\hline & Zero-trade & 55.7 & 83.6 & $\left({ }^{*}\right)$ & Italian bonds more liquid \\
\hline
\end{tabular}

EuroTLX (bonds also traded on ExtraMOT)

\begin{tabular}{|c|c|c|c|c|c|}
\hline \multirow[t]{4}{*}{ bank } & Amihud & 2.4 & 15.2 & $\left({ }^{*}\right)$ & Italian bonds more liquid \\
\hline & Roll & 37.9 & 48.6 & & Italian bonds more liquid \\
\hline & Turnover & 1.3 & 0.1 & $\left({ }^{*}\right)$ & Italian bonds more liquid \\
\hline & Zero-trade & 24.8 & 63.3 & $\left({ }^{*}\right)$ & Italian bonds more liquid \\
\hline \multirow[t]{4}{*}{ non-financial } & Amihud & 3.4 & 17.7 & $\left({ }^{*}\right)$ & Italian bonds more liquid \\
\hline & Roll & 45.9 & 37.7 & & Foreign bonds more liquid \\
\hline & Turnover & 0.7 & 0.1 & $\left({ }^{*}\right)$ & Italian bonds more liquid \\
\hline & Zero-trade & 27.8 & 59.7 & $\left({ }^{*}\right)$ & Italian bonds more liquid \\
\hline
\end{tabular}

Source: our elaborations on Consob database. ${ }^{1}$ Sample average of the liquidity indicators computed on monthly data and in percentage values. $\left(^{*}\right)=$ Null hypothesis rejected at $95 \%$ confidence level. Higher values for Amihud, Roll, zero-trade indicators mean lower liquidity levels. All non-financial bonds fragmented across DomesticMOT and EuroTLX are Italian and therefore are not eligible for the analysis herein reported. 
Table a2.3 - Liquidity by coupon structure of bank bonds fragmented across DomesticMOT and EuroTLX and of non-financial bonds fragmented across ExtraMOT and EuroTLX (percentage values)

\begin{tabular}{|c|c|c|c|c|c|}
\hline & Indicator & Plain vanilla ${ }^{1}$ & Structured $^{1}$ & Test result & Basic inference \\
\hline \multicolumn{6}{|l|}{ DomesticMOT } \\
\hline \multirow[t]{4}{*}{ bank } & Amihud & 60.2 & 27.8 & $\left({ }^{*}\right)$ & Structured bonds more liquid \\
\hline & Roll & 54.9 & 51.5 & & Same liquidity levels \\
\hline & Turnover & 4.7 & 1.5 & $\left({ }^{*}\right)$ & Plain bonds more liquid \\
\hline & Zero-trade & 14.8 & 42.5 & $\left({ }^{*}\right)$ & Plain bonds more liquid \\
\hline \multicolumn{6}{|c|}{ EuroTLX (bonds also traded on DomesticMOT) } \\
\hline \multirow[t]{4}{*}{ bank } & Amihud & 29.4 & 18.5 & $\left({ }^{*}\right)$ & Structured bonds more liquid \\
\hline & Roll & 60.6 & 40.2 & $\left({ }^{*}\right)$ & Structured bonds more liquid \\
\hline & Turnover & 0.6 & 2.0 & $(*)$ & Structured bonds more liquid \\
\hline & Zero-trade & 44.9 & 36.6 & & Same liquidity levels \\
\hline \multicolumn{6}{|l|}{ ExtraMOT } \\
\hline \multirow[t]{4}{*}{ non-financial } & Amihud & 34.2 & 12.1 & $\left({ }^{*}\right)$ & Structured bonds more liquid \\
\hline & Roll & 63.4 & 61.9 & & Same liquidity levels \\
\hline & Turnover & 0.1 & 0.3 & $(*)$ & Structured bonds more liquid \\
\hline & Zero-trade & 75.7 & 62.1 & $\left({ }^{*}\right)$ & Structured bonds more liquid \\
\hline \multicolumn{6}{|c|}{ EuroTLX (bonds also traded on ExtraMOT) } \\
\hline \multirow[t]{4}{*}{ non-financial } & Amihud & 11.4 & 6.4 & $\left({ }^{*}\right)$ & Structured bonds more liquid \\
\hline & Roll & 41.7 & 36.1 & & Same liquidity levels \\
\hline & Turnover & 0.3 & 0.6 & $\left({ }^{*}\right)$ & Structured bonds more liquid \\
\hline & Zero-trade & 50.7 & 34.5 & $\left({ }^{*}\right)$ & Structured bonds more liquid \\
\hline
\end{tabular}

Source: our elaborations on Consob database. 1Sample average of the liquidity indicators computed on monthly data and in percentage values. $(*)=$ Null hypothesis rejected at $95 \%$ confidence level. Higher values for Amihud, Roll, Zero-trade indicators mean lower liquidity levels. Both non-financial bonds fragmented across DomesticMOT and EuroTLX and bank bonds fragmented across ExtraMOT and EuroTLX are plain vanilla and therefore are not eligible for the analysis herein reported. 


\section{Appendix 3 - Estimation results}

Table a3.1 - Determinants of trade occurrence on DomesticMOT and EuroTLX

\begin{tabular}{|c|c|c|c|c|}
\hline Explicative variables & $\begin{array}{l}\text { DomesticMOT } \\
\text { Model (1) }\end{array}$ & $\begin{array}{l}\text { EuroTLX } \\
\text { Model (1) }\end{array}$ & $\begin{array}{l}\text { DomesticMOT } \\
\text { Model (2) }\end{array}$ & $\begin{array}{l}\text { EuroTLX } \\
\text { Model (2) }\end{array}$ \\
\hline Bank & $\begin{array}{c}-3.9^{* * *} \\
(1.0)\end{array}$ & $\begin{array}{l}-5.6^{* * *} \\
(1.1)\end{array}$ & $\begin{array}{c}-5.0^{* * *} \\
(1.0)\end{array}$ & $\begin{array}{l}-7.3^{* * *} \\
(1.2)\end{array}$ \\
\hline Bank ${ }^{*}$ crisis & $\begin{array}{c}0.1 \\
(0.2)\end{array}$ & $\begin{array}{c}-0.6^{* * *} \\
(0.2)\end{array}$ & $\begin{array}{c}0.1 \\
(0.2)\end{array}$ & $\begin{array}{l}-0.6^{* \star *} \\
(0.2)\end{array}$ \\
\hline Nationality & $\begin{array}{c}2.0^{* * *} \\
(0.4)\end{array}$ & $\begin{array}{c}2.9^{* * *} \\
(0.6)\end{array}$ & - & - \\
\hline Nationality ${ }^{*}$ crisis & $\begin{array}{c}0.1 \\
(0.1)\end{array}$ & $\begin{array}{c}-0.3^{* * *} \\
(0.1)\end{array}$ & - & - \\
\hline NationalityItalian sovereign Cds & - & - & $\begin{array}{c}0.0001 \\
(0.0003)\end{array}$ & $\begin{array}{l}-0.002^{* * *} \\
(0.0003)\end{array}$ \\
\hline Complexity & $\begin{array}{c}-1.4^{\star *} \\
(0.6)\end{array}$ & $\begin{array}{c}3.0^{* \star *} \\
(0.8)\end{array}$ & $\begin{array}{c}-1.5^{\star *} \\
(0.7)\end{array}$ & $\begin{array}{c}2.8^{* * *} \\
(0.9)\end{array}$ \\
\hline Complexity*crisis & $\begin{array}{l}0.01 \\
(0.1)\end{array}$ & $\begin{array}{l}0.01 \\
(0.1)\end{array}$ & $\begin{array}{c}0.09 \\
(0.09)\end{array}$ & $\begin{array}{l}-0.1 \\
(0.1)\end{array}$ \\
\hline Age & $\begin{array}{l}-0.3^{\star \star *} \\
(0.02)\end{array}$ & $\begin{array}{l}-0.5^{\star \star \star} \\
(0.02)\end{array}$ & $\begin{array}{l}-0.3^{\star * *} \\
(0.02)\end{array}$ & $\begin{array}{l}-0.5^{\star * *} \\
(0.02)\end{array}$ \\
\hline Age*crisis & $\begin{array}{l}0.1^{* * *} \\
(0.02)\end{array}$ & $\begin{array}{l}0.1^{* * *} \\
(0.02)\end{array}$ & $\begin{array}{l}0.1^{* * *} \\
(0.02)\end{array}$ & $\begin{array}{l}0.1^{* * *} \\
(0.02)\end{array}$ \\
\hline Issuer Cds & $\begin{array}{l}0.002^{* * *} \\
(0.0003)\end{array}$ & $\begin{array}{l}0.00003 \\
(0.0004)\end{array}$ & $\begin{array}{l}0.002^{* * *} \\
(0.0003)\end{array}$ & $\begin{array}{c}0.0006 \\
(0.0003)\end{array}$ \\
\hline Issuer Cds*crisis & $\begin{array}{c}-0.003^{* * *} \\
(0.0004)\end{array}$ & $\begin{array}{l}-0.0003 \\
(0.0004)\end{array}$ & $\begin{array}{l}-0.003^{* * *} \\
(0.0004)\end{array}$ & $\begin{array}{l}-0.00005 \\
(0.0004)\end{array}$ \\
\hline Information risk & $\begin{array}{l}-0.1^{* * *} \\
(0.03)\end{array}$ & $\begin{array}{l}-0.3^{* * *} \\
(0.05)\end{array}$ & $\begin{array}{l}-0.1^{* * *} \\
(0.04)\end{array}$ & $\begin{array}{l}-0.3^{\star * \star} \\
(0.05)\end{array}$ \\
\hline Information risk*crisis & $\begin{array}{l}-0.1 \\
(0.07)\end{array}$ & $\begin{array}{c}-0.3^{\star \star *} \\
(0.1)\end{array}$ & $\begin{array}{l}-0.1 \\
(0.07)\end{array}$ & $\begin{array}{l}-0.3^{\star \star \star *} \\
(0.1)\end{array}$ \\
\hline Italian stock market volatility & $\begin{array}{c}-2.4^{* * *} \\
(0.3)\end{array}$ & $\begin{array}{c}0.3 \\
(0.4)\end{array}$ & $\begin{array}{c}-2.4^{* * *} \\
(0.3)\end{array}$ & $\begin{array}{c}0.5 \\
(0.4)\end{array}$ \\
\hline Italian stock market volatility*crisis & $\begin{array}{c}0.5 \\
(0.4)\end{array}$ & $\begin{array}{c}0.4 \\
(0.5)\end{array}$ & $\begin{array}{c}0.5 \\
(0.4)\end{array}$ & $\begin{array}{c}0.5 \\
(0.5)\end{array}$ \\
\hline Constant & $\begin{array}{l}6.7^{* * *} \\
(0.9)\end{array}$ & $\begin{array}{l}4.0^{* \star *} \\
(1.0)\end{array}$ & $\begin{array}{l}8.9^{* * *} \\
(0.8)\end{array}$ & $\begin{array}{l}7.2^{\star \star *} \\
(0.9)\end{array}$ \\
\hline Number of observations & 883 & 883 & 883 & 883 \\
\hline Number of bonds & 100 & 100 & 100 & 100 \\
\hline$\rho$ & $0.5^{\star \star \star}$ & $0.7^{\star \star *}$ & $0.6^{\star * *}$ & $0.7^{* * *}$ \\
\hline
\end{tabular}

Note: “**” indicates significance at the 5\% level; “***” indicates significance at the $1 \%$ level. In parenthesis standard errors are reported. " $\rho$ " is the proportion of the total variance contributed by the panel-level component; the significance of this parameter is verified by applying a likelihood ratio test which compares the pooled estimator with the panel estimator. If " $\rho$ " is significantly different from zero, the use of panel estimation methodology is justified. Nationality is a dummy variable equal to one if the issuer of the bond is Italian; Complexity is a dummy variable equal to one if the bond is structured; Bank is a dummy variable equal to one if the bond was issued by a bank; Information risk stands for bond price volatility; Italian stock market volatility is the volatility of the FTSEMib implied in index stock prices; Crisis is a dummy variable equal to one if the risk-premium associated to low grade corporate bonds with respect to prime corporate bonds (JP Morgan Maggie European credit risk index) overcomes the $\mathrm{III}^{\circ}$ quartile of its daily distribution. 
Table a3.2 - Determinants of trade occurrence on ExtraMOT and EuroTLX

\begin{tabular}{|c|c|c|c|c|}
\hline Explicative variables & $\begin{array}{l}\text { ExtraMOT } \\
\text { Model (1) }\end{array}$ & $\begin{array}{l}\text { EuroTLX } \\
\text { Model (1) }\end{array}$ & $\begin{array}{l}\text { ExtraMOT } \\
\text { Model (2) }\end{array}$ & $\begin{array}{l}\text { EuroTLX } \\
\text { Model (2) }\end{array}$ \\
\hline Bank & $\begin{array}{l}0.02 \\
(0.2)\end{array}$ & $\begin{array}{l}-0.6^{* *} \\
(0.3)\end{array}$ & $\begin{array}{c}0.4 \\
(0.3)\end{array}$ & $\begin{array}{l}-0.2 \\
(0.4)\end{array}$ \\
\hline Bank*crisis & $\begin{array}{l}-0.05 \\
(0.04)\end{array}$ & $\begin{array}{l}-0.5^{* * *} \\
(0.04)\end{array}$ & $\begin{array}{c}0.02 \\
(0.04)\end{array}$ & $\begin{array}{l}-0.5^{\star \star *} \\
(0.04)\end{array}$ \\
\hline Nationality & $\begin{array}{c}2.4^{\star \star *} \\
(0.2)\end{array}$ & $\begin{array}{c}2.9^{* * *} \\
(0.3)\end{array}$ & - & - \\
\hline Nationality*crisis & $\begin{array}{l}0.4^{* \star *} \\
(0.04)\end{array}$ & $\begin{array}{l}0.0005 \\
(0.04)\end{array}$ & - & - \\
\hline Nationality*Italian sovereign Cds & - & - & $\begin{array}{c}-0.00006 \\
(0.0001)\end{array}$ & $\begin{array}{c}0.0002 \\
(0.0001)\end{array}$ \\
\hline Complexity & $\begin{array}{c}0.7 \\
(0.5)\end{array}$ & $\begin{array}{l}-0.2 \\
(0.7)\end{array}$ & $\begin{array}{c}0.8 \\
(0.6)\end{array}$ & $\begin{array}{l}-0.1 \\
(0.8)\end{array}$ \\
\hline Complexity*crisis & $\begin{array}{l}0.2^{* * *} \\
(0.1)\end{array}$ & $\begin{array}{c}0.05 \\
(0.08)\end{array}$ & $\begin{array}{c}0.2^{* * *} \\
(0.1)\end{array}$ & $\begin{array}{c}0.05 \\
(0.08)\end{array}$ \\
\hline Lot size & $\begin{array}{l}1.3^{* * *} \\
(0.2)\end{array}$ & $\begin{array}{c}3.2^{* * *} \\
(0.3)\end{array}$ & $\begin{array}{c}0.5^{* * *} \\
(0.2)\end{array}$ & $\begin{array}{l}2.2^{\star \star *} \\
(-0.3)\end{array}$ \\
\hline Lot size*crisis & $\begin{array}{l}0.2^{* * *} \\
(0.05)\end{array}$ & $\begin{array}{l}-0.2^{\star \star \star} \\
(0.04)\end{array}$ & $\begin{array}{l}-0.03 \\
(0.05)\end{array}$ & $\begin{array}{l}-0.2^{\star * *} \\
(0.04)\end{array}$ \\
\hline Issue size & $\begin{array}{l}0.5^{* *} \\
(0.2)\end{array}$ & $\begin{array}{c}0.8^{* * *} \\
(0.3)\end{array}$ & $\begin{array}{c}0.4 \\
(0.3)\end{array}$ & $\begin{array}{l}0.7^{* *} \\
(0.3)\end{array}$ \\
\hline Issue size*crisis & $\begin{array}{l}0.03^{\star * *} \\
(0.004)\end{array}$ & $\begin{array}{l}0.07^{* * *} \\
(0.004)\end{array}$ & $\begin{array}{l}0.04^{\star \star *} \\
(0.004)\end{array}$ & $\begin{array}{l}0.07^{* * *} \\
(0.004)\end{array}$ \\
\hline Age & $\begin{array}{l}0.1^{* * *} \\
(0.01)\end{array}$ & $\begin{array}{l}-0.4^{* \star *} \\
(0.01)\end{array}$ & $\begin{array}{l}0.1^{* * *} \\
(0.01)\end{array}$ & $\begin{array}{l}-0.4^{\star \star \star} \\
(0.01)\end{array}$ \\
\hline Age ${ }^{*}$ crisis & $\begin{array}{l}0.06^{\star * *} \\
(0.01)\end{array}$ & $\begin{array}{l}0.05^{\star \star \star} \\
(0.001)\end{array}$ & $\begin{array}{l}0.1^{* \star *} \\
(0.01)\end{array}$ & $\begin{array}{l}0.05^{\star \star \star *} \\
(0.007)\end{array}$ \\
\hline Issuer Cds quotations & $\begin{array}{c}0.002^{* * *} \\
(0.00009)\end{array}$ & $\begin{array}{l}0.004^{* \star *} \\
(0.0001)\end{array}$ & $\begin{array}{c}0.002^{* \star *} \\
(0.00009)\end{array}$ & $\begin{array}{l}0.004^{\star \star *} \\
(0.0001)\end{array}$ \\
\hline Issuer Cds quotations ${ }^{*}$ crisis & $\begin{array}{l}-0.001^{* * *} \\
(0.00009)\end{array}$ & $\begin{array}{c}-0.002^{* * *} \\
(0.0001)\end{array}$ & $\begin{array}{l}-0.001^{* * *} \\
(0.00009)\end{array}$ & $\begin{array}{c}-0.002^{* * *} \\
(0.0001)\end{array}$ \\
\hline Information risk & $\begin{array}{l}0.4^{\star * *} \\
(0.02)\end{array}$ & $\begin{array}{l}0.4^{* * *} \\
(0.03)\end{array}$ & $\begin{array}{l}0.4^{* * *} \\
(0.02)\end{array}$ & $\begin{array}{l}0.4^{* * *} \\
(0.03)\end{array}$ \\
\hline Information risk ${ }^{*}$ crisis & $\begin{array}{l}-0.3^{* * *} \\
(0.03)\end{array}$ & $\begin{array}{l}-0.5^{\star \star * *} \\
(0.03)\end{array}$ & $\begin{array}{c}-0.3^{\star * *} \\
(0.03)\end{array}$ & $\begin{array}{l}-0.5^{\star \star \star} \\
(0.03)\end{array}$ \\
\hline Italian stock market volatility & $\begin{array}{c}-2.3^{* * *} \\
(0.2)\end{array}$ & $\begin{array}{c}-3.7^{\star * *} \\
(0.2)\end{array}$ & $\begin{array}{c}-2.3^{* * *} \\
(-0.2)\end{array}$ & $\begin{array}{c}-3.7^{\star \star *} \\
(0.2)\end{array}$ \\
\hline Italian stock market volatility*crisis & $\begin{array}{c}-1.4^{* * *} \\
(0.3)\end{array}$ & $\begin{array}{c}-1.4^{* * *} \\
(0.3)\end{array}$ & $\begin{array}{c}-1.2^{* * *} \\
(0.3)\end{array}$ & $\begin{array}{c}-1.4^{* * *} \\
(0.3)\end{array}$ \\
\hline Constant & $\begin{array}{c}-14.7^{* * *} \\
(4.3)\end{array}$ & $\begin{array}{c}-18.5^{\star \star \star} \\
(6.1)\end{array}$ & $\begin{array}{c}-10.1^{* * *} \\
(5.4)\end{array}$ & $\begin{array}{c}-14.0^{* *} \\
(7.1)\end{array}$ \\
\hline Number of observations & 883 & 883 & 883 & 883 \\
\hline Number of bonds & 309 & 309 & 309 & 309 \\
\hline$\rho$ & $0.4^{* \star *}$ & $0.6^{\star \star *}$ & $0.5^{\star \star \star}$ & $0.6^{* * *}$ \\
\hline
\end{tabular}

Note: "**" indicates significance at the $5 \%$ level; “***” indicates significance at the $1 \%$ level. In parenthesis standard errors are reported. " $\rho$ " is the proportion of the total variance contributed by the panel-level component; the significance of this parameter is verified by applying a likelihood ratio test which compares the pooled estimator with the panel estimator. If " $\rho$ " is significantly different from zero, the use of panel estimation methodology is justified. Nationality is a dummy variable equal to one if the issuer of the bond is Italian; Complexity is a dummy variable equal to one if the bond is structured; Bank is a dummy variable equal to one if the bond was issued by a bank; Lot size is a dummy variable which is equal to 1 if the bond's lot size is less or equal to 1,000 euro; Information risk stands for bond price volatility; Italian stock market volatility is the volatility of the FTSEMib implied in index stock prices; Crisis is a dummy variable equal to one if the risk-premium associated to low grade corporate bonds with respect to prime corporate bonds (JP Morgan Maggie European credit risk index) overcomes the $\mathrm{III}^{\circ}$ quartile of its daily distribution. 
Table a3.3 - Estimates of marginal effects

\begin{tabular}{|c|c|c|c|c|}
\hline \multirow[t]{2}{*}{ Explicative variables } & \multicolumn{2}{|c|}{$\begin{array}{l}\text { Bonds fragmented on DomesticMOT and } \\
\text { EuroTLX }\end{array}$} & \multicolumn{2}{|c|}{$\begin{array}{l}\text { Bonds fragmented on ExtraMOT and } \\
\text { EuroTLX }\end{array}$} \\
\hline & DomesticMOT & EuroTLX & ExtraMOT & EuroTLX \\
\hline \multicolumn{5}{|l|}{ Tranquil period of time } \\
\hline Bank sector & $-0.3^{* * *}$ & $-0.5^{\star * *}$ & - & $-0.1^{* *}$ \\
\hline Nationality & $0.3^{* \star *}$ & $0.4^{* * *}$ & $0.3^{\star \star *}$ & $0.5^{\star \star *}$ \\
\hline Complexity & $-0.2^{* * *}$ & $0.4^{* * *}$ & - & - \\
\hline Lot size & - & - & $0.1^{* * *}$ & $0.5^{\star * *}$ \\
\hline Issue size & - & - & $0.06^{* \star *}$ & $0.1^{* * *}$ \\
\hline Age & $-0.05^{\star \star *}$ & $-0.08^{* \star *}$ & $0.01^{* * *}$ & $-0.07^{* \star *}$ \\
\hline $\begin{array}{l}\text { Issuer Cds quotations } \\
\text { Quotations (b.p.) }\end{array}$ & $0.0004^{* * *}$ & - & $0.0002^{* * *}$ & $0.001^{* * *}$ \\
\hline Issuer rating & $-0.01^{* * *}$ & - & $-0.003^{* *}$ & $0.04^{* * *}$ \\
\hline $\operatorname{EDF}(\%)$ & - & - & $0.01^{* * *}$ & $0.03^{* \star *}$ \\
\hline Information risk (\%) & $-0.0001^{* * *}$ & $-0.0006^{* * *}$ & $0.0003^{* * *}$ & $0.0005^{\star * *}$ \\
\hline $\begin{array}{l}\text { Italian stock market volatility } \\
(\%)\end{array}$ & $-0.004^{\star * *}$ & - & $-0.002^{\star \star *}$ & $-0.006^{\star \star *}$ \\
\hline \multicolumn{5}{|l|}{ Crisis } \\
\hline Bank sector & $-0.3^{* * *}$ & $-0.6^{* * *}$ & - & $-0.1^{* * *}$ \\
\hline Nationality & $0.3^{\star * \star}$ & $0.2^{* \star *}$ & $0.4^{\star \star \star}$ & $0.4^{* \star *}$ \\
\hline Complexity & $-0.2^{* * *}$ & $0.2^{* * *}$ & $0.1^{*}$ & - \\
\hline Lot size & - & - & $0.2^{\star \star *}$ & $0.2^{* * *}$ \\
\hline Issue size & - & - & - & $0.1^{*}$ \\
\hline Age & $-0.03^{* \star *}$ & $-0.06^{* * *}$ & $0.03^{* * *}$ & $0.06^{\star \star *}$ \\
\hline $\begin{array}{l}\text { Issuer Cds quotations } \\
\text { Quotations (b.p.) }\end{array}$ & $-0.0003^{* * *}$ & - & $6.9 e-07$ & $0.0002^{* * *}$ \\
\hline Issuer rating & $-0.02^{* * *}$ & - & $-0.005^{\star *}$ & $0.04^{\star \star *}$ \\
\hline $\operatorname{EDF}(\%)$ & - & - & $0.01^{* * *}$ & $0.04^{* * *}$ \\
\hline Information risk(\%) & $-0.0002^{* * *}$ & $-0.0006^{* * *}$ & $0.0002^{\star * *}$ & $0.0001^{* *}$ \\
\hline $\begin{array}{l}\text { Italian stock market volatility } \\
(\%)\end{array}$ & $-0.002^{\star * *}$ & - & $-0.004^{* * *}$ & $-0.005^{\star * *}$ \\
\hline
\end{tabular}

Note: Bank sector is a dummy variable which is equal to one when the issuer belongs to the banking sector; Nationality is a dummy variable which is equal to one when the issuer is an Italian firm; Complexity is a dummy variable which is equal to one when the bond is structured; Lot size is a dummy variable which is equal to one when the lot size is less or equal to 1,000 euro; Issue size is the logarithm of the amount outstanding (euro); Age is the number of trading days from the issue date; Issuer Cds quotations is expressed in basis points; Issuer rating is expressed as a score; EDF is the expected default probability expressed in percentage values; Information risk is the bond price volatility expressed in percentage values; Italian stock market volatility is the volatility of the FTSEMib implied in index stock prices expressed in percentage values. Crisis is identified when the risk-premium associated to low grade corporate bonds with respect to prime corporate bonds (JP Morgan Maggie European credit risk index) overcomes the $\mathrm{III}^{\circ}$ quartile of its daily distribution. Marginal effect is the change in the probability to have trade which corresponds to unit variation in an explicative variable by maintaining the others fixed. Regarding continuous explicative variables, average marginal effects, on the probability to have a trade, are reported. Concerning dummy variables, marginal effects represent the change in the probability to have a trade, when the explicative variable goes from zero to one. 


\section{Appendix 4}

Table a4.1 - Matched pairs of fragmented and non-fragmented bank bonds traded on DomesticMOT non-fragmented bonds

\begin{tabular}{|c|c|c|c|c|c|c|c|c|c|}
\hline ISIN & $\begin{array}{c}\text { MV } \\
\text { (bln euros) }\end{array}$ & $\begin{array}{c}\text { maturity } \\
\text { date }\end{array}$ & rating & $\begin{array}{c}\text { lot size } \\
\text { (euro) }\end{array}$ & ISIN & $\begin{array}{c}\text { MV } \\
\text { (bln euros) }\end{array}$ & $\begin{array}{c}\text { maturity } \\
\text { date }\end{array}$ & rating & $\begin{array}{r}\text { lot size } \\
\text { (euro) }\end{array}$ \\
\hline \multicolumn{10}{|c|}{ Italian structured bonds } \\
\hline IT0003035299 & 264 & 13-Dec-10 & $\mathrm{A} 2$ & 1,000 & IT0003738470 & 252 & 8-Nov-10 & $\mathrm{A} 2$ & 1,000 \\
\hline IT0004053465 & 251 & 30-Jun-11 & $\mathrm{A} 2$ & 1,000 & IT0003747505 & 259 & 19-Jun-11 & $\mathrm{A} 2$ & 1,000 \\
\hline IT0003035299 & 264 & 13-Dec-10 & $\mathrm{A} 2$ & 1,000 & IT0003747521 & 252 & 16-Nov-10 & $\mathrm{A} 2$ & 1,000 \\
\hline IT0003035299 & 264 & 13-Dec-10 & $\mathrm{A} 2$ & 1,000 & IT0003750368 & 252 & 22-Nov-10 & $\mathrm{A} 2$ & 1,000 \\
\hline IT0003035299 & 264 & 13-Dec-10 & $\mathrm{A} 2$ & 1,000 & IT0003754113 & 252 & $30-N o v-10$ & $\mathrm{~A} 2$ & 1,000 \\
\hline IT0004053465 & 251 & 30-Jun-11 & $\mathrm{A} 2$ & 1,000 & IT0003754147 & 253 & 23-Jun-11 & $\mathrm{A} 2$ & 1,000 \\
\hline IT0003035299 & 264 & 13-Dec-10 & $\mathrm{A} 2$ & 1,000 & IT0003759096 & 252 & 10-Dec-10 & A2 & 1,000 \\
\hline IT0003933154 & 99 & 16-Nov-11 & $\mathrm{A} 2$ & 1,000 & IT0003764161 & 88 & 21-Jul-11 & $\mathrm{A} 2$ & 1,000 \\
\hline IT0003035299 & 264 & 13-Dec-10 & $\mathrm{A} 2$ & 1,000 & IT0003765291 & 252 & 20-Dec-10 & $\mathrm{A} 2$ & 1,000 \\
\hline IT0003035299 & 264 & 13-Dec-10 & $\mathrm{A} 2$ & 1,000 & IT0003792741 & 252 & 20-Jan-11 & $\mathrm{A} 2$ & 1,000 \\
\hline IT0003933154 & 99 & 16-Nov-11 & A2 & 1,000 & IT0003799795 & 94 & 3-Feb-12 & A2 & 1,000 \\
\hline IT0004036338 & 213 & 28-Apr-11 & $\mathrm{A} 2$ & 1,000 & IT0003801526 & 101 & 31-Jan-11 & $\mathrm{A} 2$ & 1,000 \\
\hline IT0004036338 & 213 & 28-Apr-11 & $\mathrm{A} 2$ & 1,000 & IT0003805220 & 212 & 28-Feb-11 & A2 & 1,000 \\
\hline IT0004576556 & 99 & 22-Mar-15 & $\mathrm{A} 2$ & 1,000 & IT0003806855 & 110 & 17-Feb-15 & $\mathrm{A} 2$ & 1,000 \\
\hline IT0003933154 & 99 & 16-Nov-11 & $\mathrm{A} 2$ & 1,000 & IT0003810626 & 51 & 3-Mar-12 & $\mathrm{A} 2$ & 1,000 \\
\hline IT0004036338 & 213 & 28-Apr-11 & $\mathrm{A} 2$ & 1,000 & IT0003812523 & 65 & 28-Feb-11 & $\mathrm{A} 2$ & 1,000 \\
\hline IT0004036338 & 213 & 28-Apr-11 & A2 & 1,000 & IT0003827679 & 252 & 29-Apr-11 & A2 & 1,000 \\
\hline IT0003821136 & 147 & 31-Mar-10 & $\mathrm{A} 2$ & 1,000 & IT0003832760 & 50 & 7-Apr-10 & $\mathrm{A} 2$ & 1,000 \\
\hline IT0003821136 & 147 & 31-Mar-10 & $\mathrm{A} 2$ & 1,000 & IT0003842983 & 25 & 5-May-10 & $\mathrm{A} 2$ & 1,000 \\
\hline IT0004053457 & 218 & 15-May-11 & A2 & 1,000 & IT0003846844 & 217 & 31-May-11 & A2 & 1,000 \\
\hline IT0004713654 & 119 & 10-Jun-15 & A3 & 1,000 & IT0003855779 & 63 & 30-May-15 & A2 & 1,000 \\
\hline IT0003933154 & 99 & 16-Nov-11 & $\mathrm{A} 2$ & 1,000 & IT0003855795 & 111 & 30-Jun-11 & $\mathrm{A} 2$ & 1,000 \\
\hline IT0003740047 & 23 & 5-Oct-12 & Aa3 & 1,000 & IT0003883185 & 20 & 29-Jul-12 & $\mathrm{A} 2$ & 1,000 \\
\hline IT0003740047 & 23 & $5-O c t-12$ & Aa3 & 1,000 & IT0003890248 & 22 & 1-Sep-12 & $\mathrm{A} 2$ & 1,000 \\
\hline IT0004854490 & 19 & 7-Dec-15 & A3 & 1,000 & IT0003935241 & 127 & 6-Dec-15 & $\mathrm{A} 2$ & 1,000 \\
\hline IT0003933154 & 99 & 16-Nov-11 & $\mathrm{A} 2$ & 1,000 & IT0004057151 & 40 & 30-Jun-11 & $\mathrm{A} 2$ & 1,000 \\
\hline IT0003657563 & 322 & 31-May-14 & $\mathrm{A} 2$ & 1,000 & IT0004309313 & 362 & 30-Apr-14 & Baa1 & 1,000 \\
\hline IT0004375736 & 676 & 23-Sep-14 & $\mathrm{A} 2$ & 1,000 & IT0004315047 & 686 & 23-May-14 & Baa1 & 1,000 \\
\hline IT0004429202 & 588 & 27-Feb-15 & $\mathrm{A} 2$ & 1,000 & IT0004452386 & 556 & 28-Apr-15 & $\mathrm{A} 2$ & 1,000 \\
\hline IT0004642382 & 746 & 14-Oct-15 & A3 & 1,000 & IT0004464407 & 740 & 30-Jun-15 & A2 & 1,000 \\
\hline IT0004642382 & 746 & 14-Oct-15 & A3 & 1,000 & IT0004669138 & 1436 & 13-Dec-15 & $\mathrm{A} 2$ & 1,000 \\
\hline IT0001300992 & 95 & 22-Jan-19 & A3 & 1,000 & IT0004796451 & 101 & 3-Jun-18 & $\mathrm{A} 2$ & 1,000 \\
\hline
\end{tabular}


Table a4.1 - Matched pairs of fragmented and non-fragmented bank bonds traded on DomesticMOT

non-fragmented bonds

ISIN fragmented bonds

$\begin{array}{cccc}\text { MV } & \begin{array}{c}\text { maturity } \\ \text { date }\end{array} \text { rating } & \begin{array}{c}\text { lot size } \\ \text { (euro) }\end{array}\end{array}$

Foreign structured bonds

\begin{tabular}{|c|c|c|c|c|c|c|c|c|c|}
\hline IT0006714395 & 7 & 16-Apr-21 & $\mathrm{A} 2$ & 1,000 & $\begin{array}{l}\text { DE000UB5WF7 } \\
8\end{array}$ & 15 & 1-Apr-21 & $\mathrm{A} 1$ & 1,000 \\
\hline GB00B6HZ3D39 & 43 & 29-Jun-17 & $\mathrm{A} 2$ & 1,000 & $\begin{array}{l}\text { DE000UB8DSR } \\
5\end{array}$ & 14 & 6-Jul-17 & $\mathrm{A} 1$ & 1,000 \\
\hline GB00B6HZ2927 & 0.1 & 29-Jul-16 & $\mathrm{A} 2$ & 1,000 & DE000UU0E789 & 16 & 28-Sep-16 & $\mathrm{A} 1$ & 1,000 \\
\hline IT0004332240 & 214 & 28-Mar-12 & A3 & 1,000 & IT0004176787 & 282 & 30-Mar-12 & A3 & 1,000 \\
\hline IT0004372162 & 147 & 26-Jun-12 & A3 & 1,000 & IT0004218688 & 142 & 30-Mar-12 & A3 & 1,000 \\
\hline NL0006136376 & 11 & 28-Dec-12 & $\mathrm{A} 2$ & 1,000 & IT0006620220 & 36 & 28-Dec-12 & A3 & 1,000 \\
\hline IT0003793467 & 506 & 31-Jan-10 & A3 & 1,000 & IT0006623489 & 510 & 31-Jan-10 & Baa1 & 1,000 \\
\hline IT0006630344 & 786 & 20-Jul-13 & $\mathrm{A} 2$ & 1,000 & IT0006623620 & 531 & 3-Jun-13 & Baa1 & 1,000 \\
\hline IT0003806244 & 1010 & 28-Feb-10 & A3 & 1,000 & IT0006626201 & 1029 & 28-Feb-10 & Baa1 & 1,000 \\
\hline NL0006136376 & 11 & 28-Dec-12 & $\mathrm{A} 2$ & 1,000 & IT0006627563 & 85 & 30-Mar-13 & Baa1 & 1,000 \\
\hline IT0006636218 & 186 & 9-Jul-13 & A3 & 1,000 & IT0006628876 & 176 & 30-Mar-13 & A3 & 1,000 \\
\hline IT0006636218 & 186 & 9-Jul-13 & A3 & 1,000 & IT0006632035 & 316 & 30-Apr-13 & A3 & 1,000 \\
\hline NL0006136376 & 11 & 28-Dec-12 & $\mathrm{A} 2$ & 1,000 & IT0006632613 & 70 & 30-Apr-13 & A3 & 1,000 \\
\hline IT0006636218 & 186 & 9-Jul-13 & A3 & 1,000 & IT0006632621 & 176 & 30-Apr-13 & A3 & 1,000 \\
\hline IT0006636218 & 186 & 9-Jul-13 & A3 & 1,000 & IT0006635384 & 69 & 6-Jun-13 & A3 & 1,000 \\
\hline IT0006636218 & 186 & 9-Jul-13 & A3 & 1,000 & IT0006635475 & 127 & 31-May-13 & A3 & 1,000 \\
\hline IT0006636218 & 186 & 9-Jul-13 & A3 & 1,000 & IT0006636770 & 176 & 29-Jun-13 & A3 & 1,000 \\
\hline IT0006636218 & 186 & 9-Jul-13 & A3 & 1,000 & IT0006638057 & 69 & 29-Jun-13 & A3 & 1,000 \\
\hline IT0006636218 & 186 & 9-Jul-13 & A3 & 1,000 & IT0006638842 & 65 & 29-Jun-13 & A3 & 1,000 \\
\hline IT0006636218 & 186 & 9-Jul-13 & A3 & 1,000 & IT0006640491 & 162 & 31-Jul-13 & A3 & 1,000 \\
\hline IT0006636218 & 186 & 9-Jul-13 & A3 & 1,000 & IT0006640509 & 122 & 3-Aug-13 & A3 & 1,000 \\
\hline NL0009569821 & 15 & 27-Oct-13 & $\mathrm{A} 2$ & 1,000 & IT0006643008 & 42 & 3-Aug-13 & A3 & 1,000 \\
\hline NL0009569821 & 15 & 27-Oct-13 & $\mathrm{A} 2$ & 1,000 & IT0006643016 & 73 & 31-Aug-13 & $\mathrm{A} 3$ & 1,000 \\
\hline NL0009569821 & 15 & 27-Oct-13 & $\mathrm{A} 2$ & 1,000 & IT0006646001 & 40 & 28-Sep-13 & A3 & 1,000 \\
\hline IT0006673401 & 206 & 30-Sep-13 & $\mathrm{A} 2$ & 1,000 & IT0006646019 & 121 & 28-Sep-13 & $\mathrm{A} 3$ & 1,000 \\
\hline IT0006630344 & 786 & 20-Jul-13 & $\mathrm{A} 2$ & 1,000 & IT0006664137 & 793 & 21-Jul-14 & $\mathrm{A} 1$ & 1,000 \\
\hline NL0009058122 & 184 & 31-Jul-14 & $\mathrm{A} 2$ & 1,000 & IT0006664459 & 259 & 23-Jul-14 & $\mathrm{A} 1$ & 1,000 \\
\hline NL0009294305 & 15 & 19-Apr-17 & $\mathrm{A} 2$ & 1,000 & IT0006719584 & 36 & 21-Apr-17 & $\mathrm{A} 1$ & 1,000 \\
\hline NL0009403229 & 21 & 3-May-17 & $\mathrm{A} 2$ & 1,000 & IT0006719956 & 20 & 8-Jun-17 & A1 & 1,000 \\
\hline IT0006719816 & 15 & 30-Jun-16 & $\mathrm{A} 2$ & 1,000 & IT0006720129 & 26 & 7-Jul-16 & $\mathrm{A} 2$ & 1,000 \\
\hline NL0009597939 & 14 & 18-Oct-17 & $\mathrm{A} 2$ & 1,000 & IT0006721366 & 19 & 19-Oct-17 & $\mathrm{A} 1$ & 1,000 \\
\hline IT0006602871 & 21 & 13-Mar-16 & Baa1 & 1,000 & IT0006721473 & 20 & 3-Nov-16 & $\mathrm{A} 1$ & 1,000 \\
\hline NL0009487461 & 98 & 9-Jul-16 & $\mathrm{A} 2$ & 1,000 & NL0009537851 & 99 & 30-Sep-16 & $\mathrm{A} 2$ & 1,000 \\
\hline NL0009597939 & 14 & 18-Oct-17 & $\mathrm{A} 2$ & 1,000 & NL0009537935 & 29 & 30-Sep-17 & $\mathrm{A} 2$ & 1,000 \\
\hline NL0009487461 & 98 & 9-Jul-16 & $\mathrm{A} 2$ & 1,000 & NL0009537943 & 97 & 30-Sep-16 & $\mathrm{A} 2$ & 1,000 \\
\hline NL0009560028 & 101 & 30-Sep-17 & $\mathrm{A} 2$ & 1,000 & NL0009560010 & 97 & 30-Sep-17 & $\mathrm{A} 2$ & 1,000 \\
\hline IT0006716564 & 49 & 30-Oct-25 & $\mathrm{A} 2$ & 1,000 & XS0584356942 & 43 & 31-Jan-26 & A3 & 1,000 \\
\hline GB00B78SXC73 & 7 & 23-Mar-18 & $\mathrm{A} 2$ & 1,000 & XS0625841142 & 20 & 10-May-18 & A3 & 1,000 \\
\hline GB00B78SXC73 & 7 & 23-Mar-18 & $\mathrm{A} 2$ & 1,000 & XS0638296920 & 7 & 25-Jun-18 & A3 & 1,000 \\
\hline GB00B6HZ2927 & 0.1 & 29-Jul-16 & $\mathrm{A} 2$ & 1,000 & XS0663929619 & 15 & 7-Sep-16 & A3 & 1,000 \\
\hline
\end{tabular}

$\begin{array}{cccc}\begin{array}{c}\text { MV } \\ \text { bln euros) }\end{array} & \begin{array}{c}\text { maturity } \\ \text { date }\end{array} \text { rating } \begin{array}{c}\text { lot size } \\ \text { (euro) }\end{array}\end{array}$


Table a4.1 - Matched pairs of fragmented and non-fragmented bank bonds traded on DomesticMOT

\begin{tabular}{|c|c|c|c|c|c|c|c|c|c|}
\hline \multicolumn{5}{|c|}{ non-fragmented bonds } & \multicolumn{5}{|c|}{ fragmented bonds } \\
\hline ISIN & $\begin{array}{c}\text { MV } \\
\text { (bln euros) }\end{array}$ & $\begin{array}{c}\text { maturity } \\
\text { date }\end{array}$ & rating & $\begin{array}{c}\text { lot size } \\
\text { (euro) }\end{array}$ & ISIN & $\begin{array}{c}\text { MV } \\
\text { (bln euros) }\end{array}$ & $\begin{array}{c}\text { maturity } \\
\text { date }\end{array}$ & rating & $\begin{array}{c}\text { lot size } \\
\text { (euro) }\end{array}$ \\
\hline \multicolumn{10}{|c|}{ Italian plain vanilla bonds } \\
\hline IT0004807159 & 713 & 23-Mar-15 & . & 50,000 & IT0004596133 & 501 & 20-Apr-12 & . & 50,000 \\
\hline IT0004779713 & 293 & 30-Jun-14 & A3 & 1,000 & IT0004540719 & 717 & 20-Nov-14 & A2 & 1,000 \\
\hline IT0004855554 & 36 & 30-Nov-14 & A3 & 1,000 & IT0004540842 & 38 & 20-Nov-14 & $\mathrm{A} 2$ & 1,000 \\
\hline IT0004842370 & 525 & 8-Oct-19 & A3 & 1,000 & IT0004608797 & 373 & 14-May-20 & $\mathrm{A} 2$ & 1,000 \\
\hline IT0004842370 & 525 & 8-Oct-19 & A3 & 1,000 & IT0004645542 & 315 & 15-Nov-20 & A2 & 1,000 \\
\hline IT0004780711 & 97 & 29-Jun-14 & A3 & 1,000 & IT0004725559 & 76 & 14-Jul-14 & A2 & 1,000 \\
\hline IT0001223889 & 274 & 8-May-13 & $\mathrm{A} 2$ & 1,000 & IT0004760721 & 512 & 2-Sep-13 & A2 & 1,000 \\
\hline IT0004842370 & 525 & 8-Oct-19 & A3 & 1,000 & IT0004863723 & 154 & 18-Oct-19 & A2 & 1,000 \\
\hline \multicolumn{10}{|c|}{ Foreign plain vanilla bonds } \\
\hline IT0004618507 & 22 & 28-Jun-16 & A3 & 1,000 & IT0006719428 & 18 & 14-Apr-16 & A2 & 1,200 \\
\hline IT0004618507 & 22 & 28-Jun-16 & A3 & 1,000 & IT0006719436 & 36 & 14-Apr-16 & A2 & 1,400 \\
\hline IT0004618507 & 22 & 28-Jun-16 & A3 & 1,000 & IT0006719444 & 44 & 14-Apr-16 & A2 & 1,000 \\
\hline IT0004698178 & 278 & 3-Jul-16 & A3 & 1,000 & NL0009354505 & 201 & 22-Feb-16 & $\mathrm{A} 2$ & 1,000 \\
\hline IT0004650781 & 79 & 22-Oct-20 & A3 & 1,000 & NL0009483825 & 251 & 22-Jun-20 & $\mathrm{A} 2$ & 1,000 \\
\hline DE000UB2F5S4 & 74 & 29-Jul-17 & $\mathrm{A} 1$ & 1,000 & NL0009560002 & 93 & 30-Sep-17 & $\mathrm{A} 2$ & 1,000 \\
\hline IT0004650781 & 79 & 22-Oct-20 & $\mathrm{A} 3$ & 1,000 & NL0009694272 & 101 & 14-Feb-21 & $\mathrm{A} 2$ & 1,000 \\
\hline
\end{tabular}


Table a4.2 - Liquidity indicators for banks bonds traded on DomesticMOT by fragmentation (average percentage values over the sample period; January 2010 - June 2013)

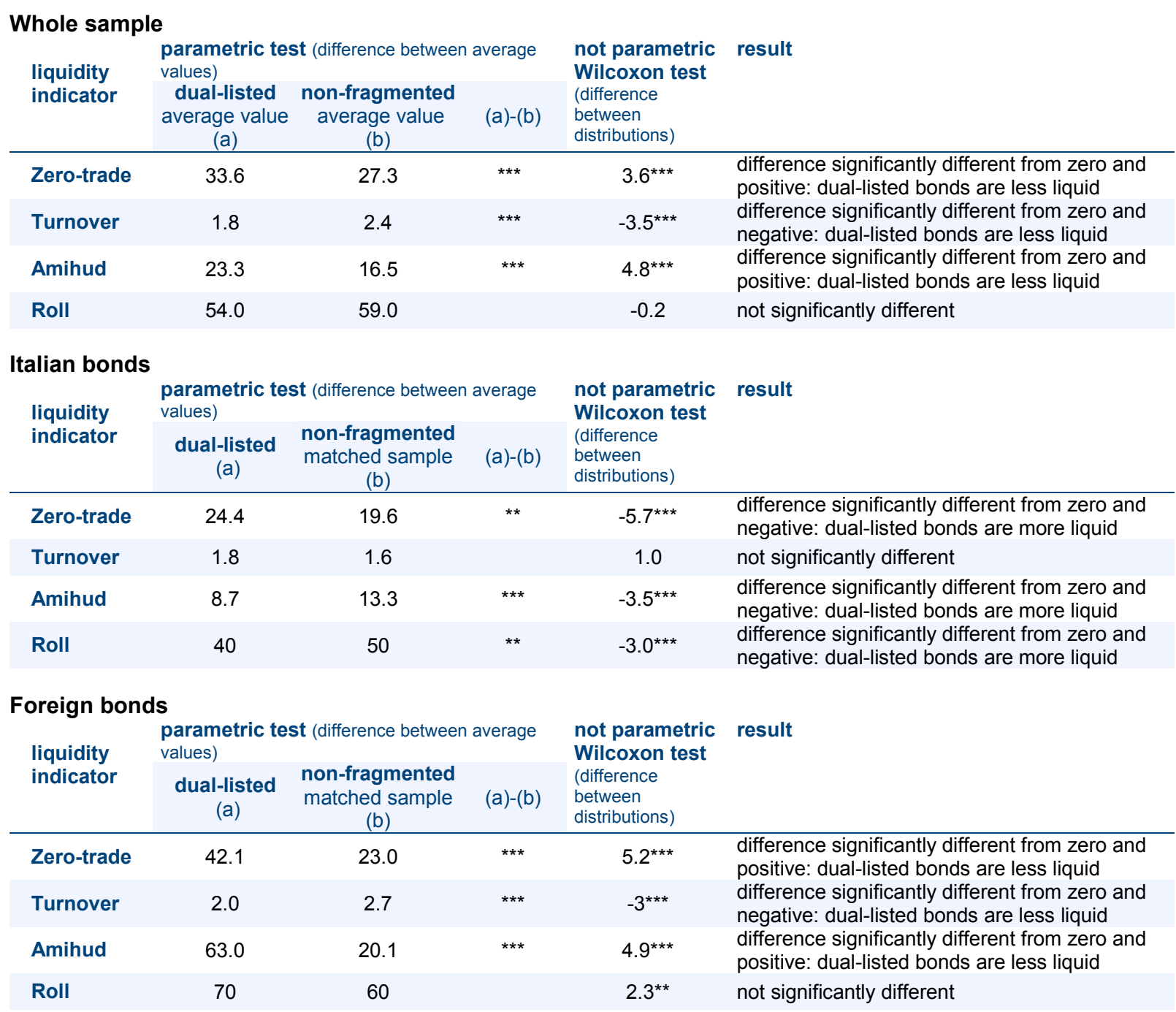

Note: Non fragmented bonds are matched pairs with dual-listed securities on the basis of market value, maturity, rating, complexity, nationality of the financial instruments. $(* * *)$ indicates that the difference between dual-listed and not fragmented bonds is significant at the $1 \%$ level; $(* *)$ indicates that the difference between dual-listed and not fragmented bonds is significant at the $5 \%$ level.

Table a4.3 - Test of homogeneity between matched pairs

\begin{tabular}{lcccc} 
& \multicolumn{2}{c}{ whole sample } & Italian bonds & \\
& F-statistic & P-value & F-statistic & P-value \\
\hline market value & 2.3 & 0.07 & 1.4 & 0.3 \\
rating & 1.1 & 0.4 & 0.8 & 0.6 \\
maturity & 0.8 & 0.5 & 2.2 & 0.1
\end{tabular}

In the table we report F-statistics applied to the coefficients of a multivariate regression in which the relations among differences between matched pairs liquidity indicators and differences between matched pairs characteristics (market value, rating, maturity) are examined. The F-statistic allows to test the hypothesis that all the coefficients are jointly equal to zero. 